\title{
Investigating Repetitive Reaction Pathways for the Formation of Polycyclic Aromatic Hydrocarbons in Combustion Processes
}

\author{
N. Hansen,,$^{1 *}$ M. Schenk,${ }^{2 \dagger}$ K. Moshammer, ${ }^{2 \ddagger}$ K. Kohse-Höinghaus ${ }^{2}$ \\ ${ }^{1}$ Combustion Research Facility, Sandia National Laboratories, Livermore, CA 94551, USA \\ ${ }^{2}$ Department of Chemistry, Bielefeld University, D-33615 Bielefeld, Germany
}

submitted to:

Combustion and Flame

39 Pages

9 Figures

Supplementary Material is available.

\footnotetext{
* Corresponding author: Nils Hansen; phone: +1 925294 6272; email: nhansen@ @andia.gov

${ }^{\dagger}$ Current address: Institut für Technische Verbrennung, RWTH Aachen University, Templergraben 64, 52056 Aachen, Germany

* Current address: Combustion Research Facility, Sandia National Laboratories, Livermore, CA 94551, USA
} 


\begin{abstract}
Repetitive hydrogen-abstraction and methyl- and acetylene-addition reaction sequences that contribute to the formation and growth of polycyclic aromatic hydrocarbons (PAHs) during incomplete combustion processes have been analyzed in flame-sampled electron ionization mass spectra. Specifically, we analyzed the range from $\mathrm{C}_{6} \mathrm{H}_{6}$ to $\mathrm{C}_{16} \mathrm{H}_{10}$ in the mass spectra obtained from atmospheric-pressure opposed-flow flames fueled by $n$-butane, $i$-butane, and $i$-butene, with conditions identical to those chosen by Schenk et al. [Proc. Combust. Inst. 35 (2015) 17611769]. To assist the interpretation of the complex flame-sampled mass spectral data, this work elucidates the possibility for providing mechanistic insights from a simple analysis approach that does not convert the mass spectral data into isomer-resolved mole fraction profiles but solely is based on signal strength and ratios. While such an approach has not been exploited before, it is shown in this work that the repetitive nature of the observed quantitative signal ratios in the methyl- and acetylene-addition reaction sequences provides interesting insights into the overall features of flame-sampled mass spectra and the growth chemistry of PAHs. For the flames studied here, the similarity between the spectra obtained from the three different flames suggests that the signal ratios in the covered range are not fuel-structure dependent and that it is possible to draw mechanistic conclusions without knowing the isomer-specific chemistry. For example, the chemical growth pathways supported by this work suggest that other isomers besides pyrene contribute to the measured signal at $m / z=202 \mathrm{u}\left(\mathrm{C}_{16} \mathrm{H}_{10}\right)$, a result that adds concern regarding the general validity of the assumption of pyrene dimerization as the particle inception step.
\end{abstract}




\section{Introduction}

The molecular growth of small precursor molecules to large polycyclic aromatic hydrocarbons (PAHs) in combustion environments receives continuing attention in combustion chemistry research [1-6]. The motivation behind this interest stems from the facts that PAHs, which are generally considered precursors for soot particles, are byproducts of incomplete combustion processes and are known to be harmful to humans and the environment [7-11]. Because anthropogenic activities, including combustion processes, cause major PAH emissions into the atmosphere [12], understanding the formation pathways that lead to PAHs will eventually help to reduce the emission of these substances and to develop a model for soot particle inception.

A chemical understanding of and a predictive combustion chemistry model for PAH formation are based on two pillars, i.e., an accurate description of the formation of the so-called "first aromatic ring" and the subsequent characterization of the molecular growth reactions towards PAHs. It is evident that the predictive capabilities of the PAH sub-model rely on the accuracy of the description of the formation of the first aromatic ring. Already this first step in the overall soot formation process can be very complex: Normally, benzene is considered to be this first aromatic ring and its formation is generally described by reactions of resonantly stabilized radicals like propargyl $\left(\mathrm{C}_{3} \mathrm{H}_{3}\right)$, allyl $\left(\mathrm{C}_{3} \mathrm{H}_{5}\right)$, $i-\mathrm{C}_{4} \mathrm{H}_{5}$, and cyclopentadienyl $\left(\mathrm{C}_{5} \mathrm{H}_{5}\right)[5$, 13-19]. However, precursors and reactions have been identified that can form aromatic species without passing through benzene, and it is therefore important to note that benzene is not necessarily the first aromatic ring [5, 6]. Noteworthy examples are the proposed formation routes of naphthalene via the reaction of two cyclopentadienyl $\left(\mathrm{C}_{5} \mathrm{H}_{5}\right)$ radicals or the formation of benzyl and toluene via the ring-enlargement $\mathrm{C}_{5} \mathrm{H}_{5}+\mathrm{C}_{2} \mathrm{H}_{2}$ reaction [20, 21]. Toluene, 
phenylacetylene, and styrene can also be formed directly through various other reactions of $\mathrm{C}_{4} \mathrm{H}_{5}$ and $\mathrm{C}_{5} \mathrm{H}_{3}$ radicals [22-24]. Further complexity is added by the fact that the importance of these various formation pathways is likely to depend on the fuel structure [13, 25].

In contrast, many combustion chemistry models describing the PAH growth chemistry from the first aromatic ring consider a repetitive sequence of hydrogen-abstraction and $\mathrm{C}_{2} \mathrm{H}_{2}$ (acetylene)-addition reactions, the so-called HACA mechanism [26]. This description is based on the original work of Frenklach and Wang [27] and was later updated by Appel et al. [28]. However, compelling evidence is now accumulating in the literature that the HACA mechanism alone cannot provide an accurate description of the molecular growth chemistry. For example, it was shown that this HACA mechanism is too slow to account for the very fast process of PAH formation [29, 30], that HACA is not needed to promote growth of large PAHs [31], and that PAHs can be formed in non-sequential order [32-35]. In addition, Kislov et al. showed that the HACA mechanism produces mostly cyclopenta-fused PAHs instead of PAHs with six-member rings only [36].

To overcome these limitations, many other reactions have been considered to contribute to PAH formation. For example, Panariello et al. identified not only the above discussed HACA steps in flame-sampled mass spectra but also C- and/or $\mathrm{CH}_{2}$-addition reactions [37]. Similarly, Shukla and Koshi suggested methyl addition/cyclization reactions to be important [38, 39] and Yoon et al. also emphasized the role of methyl radicals for the formation of PAHs [40, 41]. Other radical species discussed in the literature that might contribute to PAHs include vinyl [42], propargyl [30, 43-45], cyclopentadienyl [30, 43, 45, 46], and aromatic ring radicals [38, 47, 48]. Reactions of vinylacetylene with aromatic radicals contributing to ring-formation chemistry were discussed, for example, in Refs. [28, 43, 45]. It is conceivable that the importance of these 
various reactions depends on the fuel structure, as it was shown to be the case for the formation of the first aromatic ring.

The present work is intended to shed further light on repetitive growth sequences in PAH formation chemistry and builds upon the studies of Panariello et al.[37], Shukla and coworkers [38, 39], and Schenk et al. [49] in which repetitive sequences of acetylene and methyl additions were qualitatively identified as molecular-weight growth reactions via signal patterns in mass spectrometric experiments. This study elucidates the possibility of gaining information about the PAH growth process not just from the signal patterns but additionally from quantitative signal intensities. This approach is related to the earlier work [25], in which experimentally determined peak mole fractions of $\mathrm{C}_{3} \mathrm{H}_{3}, \mathrm{C}_{4} \mathrm{H}_{5}$, and $\mathrm{C}_{5} \mathrm{H}_{5}$ were correlated to $\mathrm{C}_{6} \mathrm{H}_{6}$ mole fractions to unravel benzene formation pathways in premixed flames.

It is outlined here, that a simplistic analysis of the signal intensities in the flame-sampled gas-phase mass spectra taken from atmospheric-pressure opposed-flow flames fueled by $n$ butane, $i$-butane, and $i$-butene might allow for gaining some insights into the PAH growth chemistry up to the $\mathrm{C}_{16} \mathrm{H}_{10}$ intermediates without the full knowledge of the detailed chemistry of isomer-resolved chemical structures. Such a simplified approach, in which the mass spectral signal is intentionally not converted into isomer-resolved mole fraction profiles, might become important because both the exponential growth of the number of isomers with the size of the molecular structure and the scarcity of calibration or cross section information preclude such comprehensive isomer-resolved analysis for the growth of larger PAHs. The presented concept is supported by the recent observation that the ratios of the maximum toluene and benzene mole fractions are constant in many flames of a variety of different fuels [50]. 
The new insights are intended to assist in connecting species measurements in nonpremixed flames with the ongoing efforts in the soot community to develop flame chemistry models, that are often also relying on lumping, i.e. not isomer-specific, approaches, for PAH formation.

\section{Experimental Procedures}

For the purpose of this paper, i.e., to elucidate the possibilities to gain chemical information about PAH formation from signal intensities in flame-sampled mass spectra without resolving the details of isomeric contributions, we recorded mass spectra from opposed-flow diffusion flames of $n$-butane, $i$-butane, and $i$-butene. The flame conditions were identical to the ones reported in Ref. [49] and are provided here only as Supplementary Material. The fuels were chosen because their respective combustion chemistry are interesting research topics as outlined in Refs. [51-53] and further details are therefore not provided here. From the chemical point-ofview the selected fuels represent different chemical structures including isomeric long-chain (normal) and branched (iso) alkanes, and a branched (iso) alkene.

The experimental approach used to record the flame-sampled mass spectra has been detailed in Ref. [49]. In short, opposed-flow fuel-Ar/ $\mathrm{O}_{2}-\mathrm{Ar}$ diffusion flames were established at atmospheric pressure between the two outlets of a home-built burner system [54] while regulating the respective gas flows with an absolute precision of $\pm 0.5 \%$ using calibrated mass flow controllers. The conditions were optimized to establish flames that provide sufficient signal for the investigated mass range up to $m / z=202 \mathrm{u}$ while simultaneously avoid clogging of the sampling probe. The conditions result in slightly sooting flames as indicated by the observed orange incandescence. The adiabatic peak temperatures are calculated to be $2100( \pm 100) \mathrm{K}$ using 
three different models $[44,55,56]$. The results of these calculations are summarized in the Supplementary Material. The $i$-butene flame is calculated to be the coldest with temperatures in the range of $2020 \mathrm{~K}( \pm 15 \mathrm{~K})$, while the $n$-butane flame is the hottest with temperatures calculated to be between $2196 \mathrm{~K}( \pm 11 \mathrm{~K})$. It is discussed later that the small differences in the peak flame temperature do not alter the conclusions.

In order to probe the chemical details of the opposed-flow flames and to eventually guide the model development, gases were sampled from the center-line of the flame configurations as function of the distance from the fuel outlet via a microprobe with a $\sim 20 \mu \mathrm{m}$ orifice into a differentially pumped molecular-beam mass spectrometer, as described previously [49, 57]. Keeping the sampling probe fixed, flame-sampling from any axial position of the flame was achieved with an accuracy of $0.5 \mathrm{~mm}$ by vertically moving the entire burner assembly using a computer-controlled high-precision $(0.05 \mathrm{~mm})$ stepper motor. The given accuracy, which mainly results from the uncertainty in the determination of the zero-point, i.e., "Distance from the Fuel Outlet" $=0 \mathrm{~mm}$, implies that the provided experimental data might be shifted by this amount; a technique widely accepted in premixed flame experiments in order to achieve spatial agreement with modeling results $[58,59]$. In contrast, the spatial resolution of the measurements is mainly determined by the diameter of the microprobe's orifice.

The mass spectrometer was equipped with electron ionization (EI) and the ions were pulse-extracted into the time-of-flight region, separated by their mass-to-charge $(\mathrm{m} / \mathrm{z})$ ratio, and subsequently detected using a multi-channel plate detector with a multi-channel scaler for data recording. The sensitivity limit of $\sim 1 \mathrm{ppm}$, a dynamic range of $10^{6}$, and the mass resolution of $m / \Delta m \sim 2500$ of the custom-built reflectron time-of-flight mass spectrometer enabled the detection of many PAH species [49] and their separation from oxygenated intermediates. The 
width of the electron's energy distribution ( $\sim 2 \mathrm{eV}$ full width at half maximum) precluded isomerresolved EI measurements; however, a limited number of isomer-resolving gas chromatographic experiments for these flames were reported in Ref. [49].

Experimental artifacts related to probe interferences, e.g. flow field, temperature, chemical modification, have been reported [60-63], but given the scientific goals of this work, flame-sampling molecular-beam mass spectrometry is an indispensable tool to provide the required chemical information on the PAH intermediates, because it allows for the detection of all targeted intermediates simultaneously $[58,59,64]$. The extent to which the flame chemistry is altered and the chemical reactions are quenched when sampling through the microprobe has not yet been quantified. However, for the relative comparisons in this paper the experimental and analysis procedures are the same for the three different flames discussed here.

The relation between signal intensity and mole fractions for the sum of the same-mass species is given by [58, 65]:

$$
\mathrm{S}_{\mathrm{m}} \sim \Sigma\left[\mathrm{x}_{\mathrm{i}} \times \sigma_{\mathrm{i}}(\mathrm{E})\right] \times \mathrm{D}_{\mathrm{m}} \times \Phi(\mathrm{E}) \times \mathrm{F}(\mathrm{T})
$$

where $S_{\mathrm{m}}$ is the integrated ion count recorded for the flame species at a given $m / z$ value, $x_{i}$ is the species mole fraction with $\sigma_{\mathrm{i}}(\mathrm{E})$ being the corresponding ionization cross section at the electron energy E. $\mathrm{D}_{\mathrm{m}}$ is the mass discrimination factor for the species at $m / z, \Phi(E)$ is the electron current and $\mathrm{F}(\mathrm{T})$ is an instrumental sampling function that links the molar density in the molecular beam to the local flame temperature.

The quantitative mole fractions provided below for $\mathrm{CH}_{4}$ and $\mathrm{C}_{2} \mathrm{H}_{2}$ were determined from a comparison of their respective signal ratios to Ar in a cold-gas mixture of known composition to ratios measured in the flames. Their uncertainties are expected to be within $\pm 25 \%$. 


\section{Results and Discussion}

(a) General Description of the Procedures

In a first step, multiple flame-sampled mass spectra were obtained as described above by moving the burner assembly in the vertical direction to allow for sampling at different flame positions. A typical flame-sampled mass spectrum from within the atmospheric-pressure opposed-flow flames is shown in Fig. 1 for the case of the $i$-butane flame. In the soot-forming region of the flame, strong signal was observed in the range between $m / z=2 \mathrm{u}\left(\mathrm{H}_{2}\right)$ and $60 \mathrm{u}$ (the $\mathrm{C}_{4}$-species). Increasingly weak signal was detectable up to $m / z=202 \mathrm{u}\left(\mathrm{C}_{16} \mathrm{H}_{10}\right)$. Similar spectra were recorded for the flames fueled by $n$-butane, and $i$-butene and are shown in the Supplementary Material.

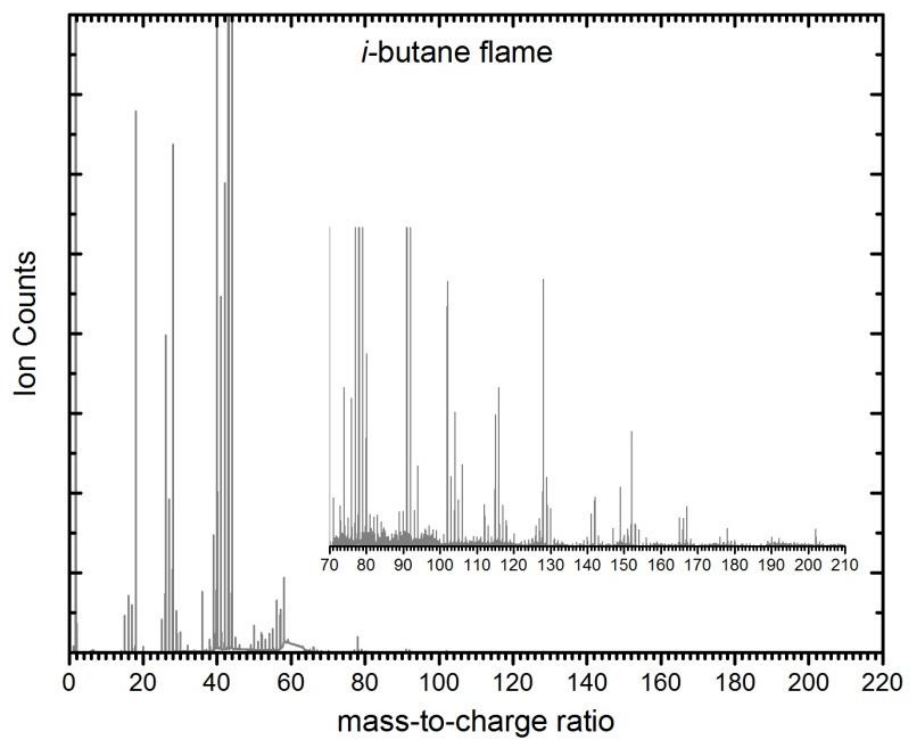

Figure 1: Flame-sampled mass spectrum from within the atmospheric-pressure opposed-flow $i$ butane flame in the mass-to-charge ratio up to $220 \mathrm{u}$.

From such data, mole fraction profiles as a function of distance from the fuel outlet can be generated based on procedures described elsewhere [51, 65]. As an example, we determined the $\mathrm{CH}_{4}$ and $\mathrm{C}_{2} \mathrm{H}_{2}$ mole fraction profiles for the three flames as shown in Fig. 1. It can be seen 
that the maximum $\mathrm{CH}_{4}$ mole fraction $\left(\sim 3 \times 10^{-3}\right)$ is, within the experimental uncertainties, similar for all three flame. For $\mathrm{C}_{2} \mathrm{H}_{2}$, the mole fraction profiles peak around 0.009 , with the highest measured concentration in the $n$-butane flame and the lowest concentration in the $i$-butene flame. However, the experimental $\mathrm{C}_{2} \mathrm{H}_{2}$ mole fraction profiles can be considered non-distinguishable given the above-mentioned experimental uncertainty of $\pm 25 \%$.

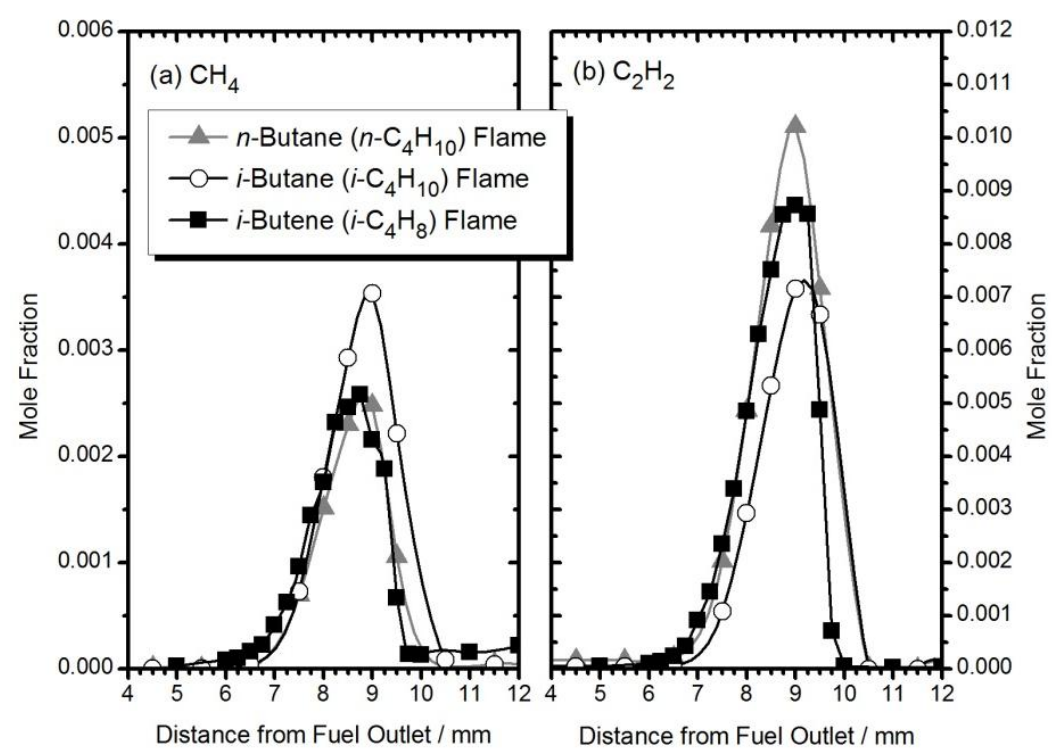

Figure 2: Mole fraction profiles as function of distance from the fuel outlet for $\mathrm{CH}_{4}$ and $\mathrm{C}_{2} \mathrm{H}_{2}$ as measured in the $n$-butane, $i$-butane, and $i$-butene flames.

Although $\mathrm{C}_{0}$ through $\mathrm{C}_{6}$ species are routinely quantified in flame-sampling mass spectrometric experiments, this is not the purpose of the present paper. Instead, the fundamental basis for the discussion presented below is the realization that a complete isomer-selective interpretation of the signal in the flame-sampled mass spectra that relates to $\mathrm{C}_{6}$ and heavier species is currently still challenging. For example, it has been pointed out that isomer-identifying measurements with flame-sampling mass spectrometry employing synchrotron-generated vacuum-ultraviolet photons are currently limited, with some exceptions, to molecules with up to six heavy atoms $[58,59,66,67]$. And, for isomer-resolving gas-chromatographic measurements 
the chemical structures need to be known in order to choose the appropriate separating column. It is obvious that any experimental method suffers from the incredibly large number of conceivable isomers. For example, Ref. [59] shows that more than sixty isomers are conceivable for $\mathrm{C}_{6} \mathrm{H}_{6}$ with that number increasing exponentially with molecular size. Given the lack of isomer-specific information, it is therefore not intended and currently not possible to present a complete analysis of isomeric structures that potentially contribute to a single $m / z$ value beyond $m / z=78$. Mole fraction profiles as function of the distance to the fuel outlet of individual PAH isomers will therefore not be reported here and we can only provide integrated ion counts for a specific $\mathrm{m} / \mathrm{z}$ value as function of distance to the fuel outlet as exemplarily shown in Fig. 3.

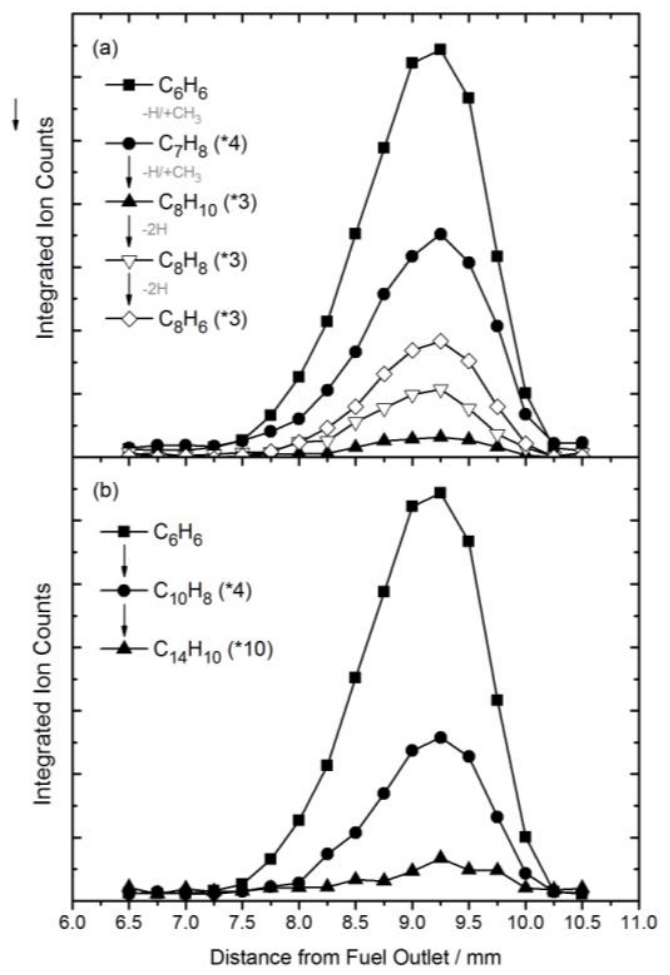

Figure 3: (a) Integrated ion counts of $m / z=78 \mathrm{u}\left(\mathrm{C}_{6} \mathrm{H}_{6}\right), 92 \mathrm{u}\left(\mathrm{C}_{7} \mathrm{H}_{8}\right), 102 \mathrm{u}\left(\mathrm{C}_{8} \mathrm{H}_{6}\right), 104 \mathrm{u}$ $\left(\mathrm{C}_{8} \mathrm{H}_{8}\right)$, and $106 \mathrm{u}\left(\mathrm{C}_{8} \mathrm{H}_{10}\right)$ as function of distance from the fuel outlet and (b) of $\mathrm{m} / \mathrm{z}=78 \mathrm{u}$ $\left(\mathrm{C}_{6} \mathrm{H}_{6}\right), 128 \mathrm{u}\left(\mathrm{C}_{10} \mathrm{H}_{8}\right)$, and $178 \mathrm{u}\left(\mathrm{C}_{14} \mathrm{H}_{10}\right)$. As discussed in the text, the thickness of the flame front and the spatial resolution of the sampling technique preclude a confirmation of the anticipated sequence of chemical growth pathways. 
It should also be pointed out that the compilation of chemically detailed mechanisms is also hampered by the number of possible species and the lack of their kinetic and thermodynamic parameters. In addition, the suitability of large mechanisms to extract chemical information has been questioned given the experimental uncertainties and the accuracies of thermodynamic, transport, and kinetic input data [68].

In a second step of the analysis procedure, we therefore intentionally simplify the interpretation of the mass spectra in order to potentially gain insights into the molecular-weight growth chemistry and to provide tools for interpreting the general features of flame-sampled mass spectra. To this end, we provide an approach that focuses on quantitative signal and signal ratio interpretation in the flame-sampled mass spectra at certain $\mathrm{m} / \mathrm{z}$ values in the range from 78 to 202. In the following discussion we only focus on the mass spectra taken at the position with the strongest signal for the targeted species.

As discussed above, a species' signal in a mass spectrum is proportional to the species' concentration, each observed signal in the flame-sampled mass spectra is directly proportional to the sum of the concentrations of the species with the respective mass (Eq. 1). For the PAH intermediates, we now interpret the signals with the assumption of identical ionization cross sections for all possible species while neglecting fragmentation caused by ionization. These assumptions appear to be justifiable simplifications given the ambiguity of the isomeric composition and the scarcity of reliable total and partial ionization cross sections for many higher-mass intermediates. Knowing that the mass discrimination factors are constant over a wide range [51], the signal ratios of two mass peaks ( $\mathrm{m}$ and $\mathrm{m}$ ') in a single mass spectrum taken at any given position in the flame is expressed as:

$$
\mathrm{S}_{\mathrm{m}} / \mathrm{S}_{\mathrm{m}^{\prime}}=\mathrm{x}_{\mathrm{m}} / \mathrm{x}_{\mathrm{m}},
$$


where $\mathrm{x}_{\mathrm{m}}$ and $\mathrm{x}_{\mathrm{m}}$, are the sums of the mole fractions of all the species contributing to the respective mass peaks.

Specifically, we break down the complex data structure of the flame-sampled mass spectra in the range from $m / z=78 \mathrm{u}\left(\mathrm{C}_{6} \mathrm{H}_{6}\right)$ to $m / z=202 \mathrm{u}\left(\mathrm{C}_{16} \mathrm{H}_{10}\right)$ by interpreting only sequential growth sequences that are related to H-abstraction-methyl-addition reactions as described in Ref. [39] and the well-known H-abstraction-acetylene-addition scheme. As shown in the following paragraphs, the observed signal (i.e., mole fraction) ratios within the growth sequences provide valuable insights into the ongoing chemistry. Other proposed reaction schemes, i.e., reactions involving cyclopentadienyl and indenyl radicals, as proposed by Marinov et al. [53], are not discussed here because repetitive sequences of these precursor molecules were not identified in the examined mass range.

\section{(b) H-Abstraction-Methyl-Addition (HAMA) Sequence}

The flame-sampled mass spectra recorded in this work, an example for which was given in Fig. 1, exhibit mass peaks at a recurrent interval of $14 \mathrm{u}$, starting at $m / z=78 \mathrm{u}$ (considered to be mainly benzene). A corresponding sequence from the $i$-butane flame is presented in Fig. 4 in the first row. Under the given conditions, this recurrent feature probably corresponds to an H-abstraction-methyl-addition (HAMA) reaction scheme as outlined in Ref. [39]. Because we purposely do not perform an isomer-specific analysis, the chemical structures of species (or classes of species) shown are only provided to facilitate the discussion of the chemical growth pathways. 


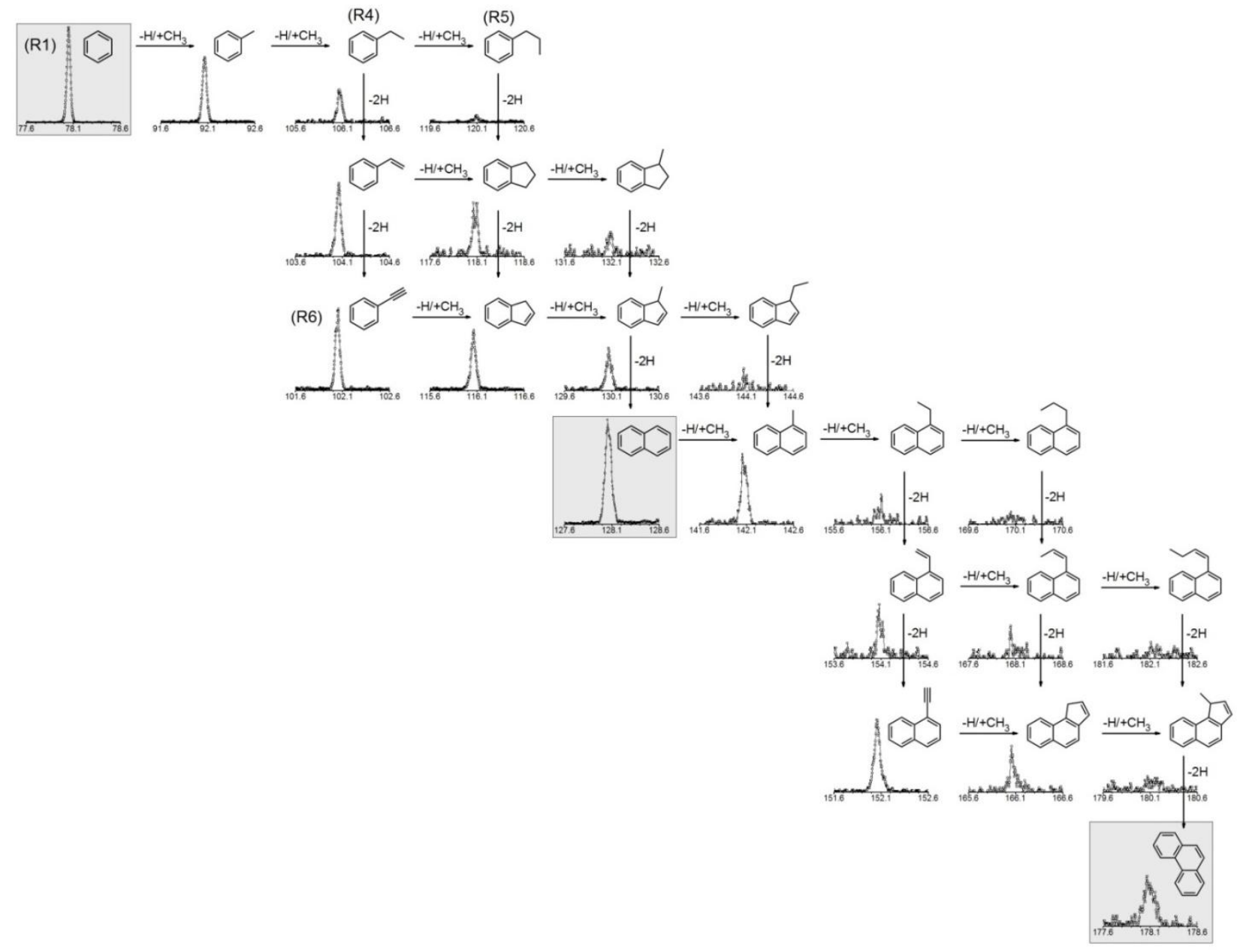

Figure 4: Repetitive HAMA sequences of hydrogen-abstraction-methyl-addition reactions in the flame-sampled mass spectra of the $i$-butene flame. Similar spectra were recorded for the other flames fueled by $n$-butane and $i$-butane. The intensities, which are off-scale, decrease in any given row from left to right, while intensities increase from top to bottom for the signals related to the $-2 \mathrm{u}$ steps. The given molecular structures are thought to provide guidance on some of the structures to be expected; isomeric forms are meant to be included as well. Single-, double-, and triple-ring aromatic species are $m / z=78,128$, and $178 \mathrm{u}$ are highlighted as well as the reactions that are discussed in more detail in the text.

Generally speaking, methyl radicals can react in interesting ways with aromatic species as demonstrated in the following: (a) they can form side chains (R1), (b) they are potentially important to form five-membered ring structures by bridging the so-called arm-chair 
configuration, thus forcing PAHs to be non-planar (R2), and (c), methyl radicals can also promote ring enlargement reactions by converting five-membered into six-membered ring structures (R3). Simple examples of these reaction classes are shown in the following scheme:

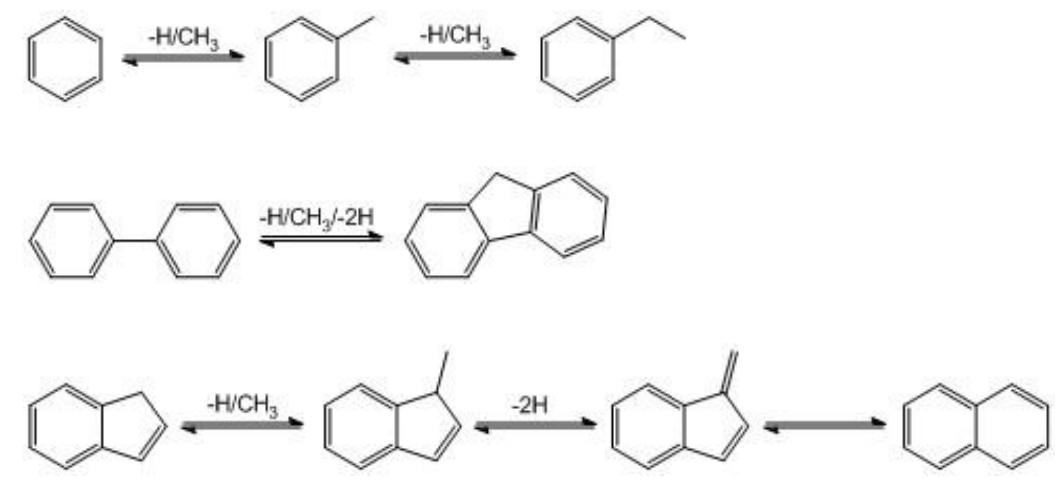

The results in Fig. 4 indicate that these HAMA sequences seem to end after two or three repetitive steps. In other words, larger members of the respective sequences are not formed in concentrations above the detection limit ( 1 ppm). For example, the first row in Fig. 4 indicates that starting at $m / z=78 \mathrm{u}$, the HAMA sequence can lead to intermediates at $m / z=92 \mathrm{u}, 106 \mathrm{u}$, and $120 \mathrm{u}$ before the signal is in the order of the noise level at $\mathrm{m} / \mathrm{z}=134 \mathrm{u}$ (not shown). One possible explanation for this observation would be that steric effects preclude the addition of a fourth methyl radical to the aromatic ring structure. While this statement could certainly be the case for the benzene sequence, this explanation might not hold for the sequences starting at naphthalene or any larger molecule. But the sequences starting from higher-mass molecules, e.g., at $m / z=128 \mathrm{u}, 152 \mathrm{u}$, or $154 \mathrm{u}$ also end after three methyl addition steps. Therefore the flamesampled mass spectra indicate that the presence of ethyl- and propyl-derivatives (i.e., a single alkyl chain) is more likely than the presence of the respective di-methyl and ethyl-methyl isomers, although the latter ones cannot be excluded. The formation of $\mathrm{C}_{2}-$ and $\mathrm{C}_{3}$ alkyl side chains is probably a consequence of the stability of the, for example, $\mathrm{C}_{6} \mathrm{H}_{5} \mathrm{CH}_{2}$ (benzyl) radical 
in comparison to the isomeric $\mathrm{C}_{6} \mathrm{H}_{4} \mathrm{CH}_{3}$. The mass spectra indicate that the HAMA sequences are terminated once a propyl derivative is formed.

Shukla et al. pointed out that at this stage, further methyl addition reactions are likely to compete with dehydrogenation and cyclization steps [39]. Such reactions can occur at the high temperatures of the flame $(2000 \mathrm{~K})$ to convert saturated alkyl aromatics into more stable dehydrogenated and cyclic products. Evidence for these product species was prominently found in the mass spectra at $2 \mathrm{u}$ mass units below the respective alkyl-aromatic species. These reactions are indicated in the columns of Fig. 3 and shown in reactions (R4) and (R5) for ethyl-benzene forming phenylacetylene via styrene and propyl-benzene forming indene via 2,3-dihydro- $1 \mathrm{H}-$ indene as examples:

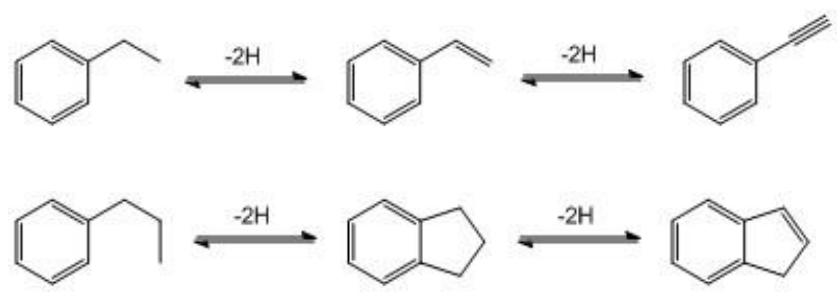

The above description is consistent with the predictions of Stein and Fahr [69] that condensed aromatic species are thermodynamically more stable than alkyl-aromatics.

The reaction scheme as shown in Fig. 3 and outlined in reactions (R1)-(R5) shows how methyl radical reactions in combination with dehydrogenation and cyclization steps contribute systematically towards the growth of small aromatic species to larger PAHs. It is important to note that methyl radical reactions are essential to explain the high density of peaks with a spacing of $14 \mathrm{u}$ and $2 \mathrm{u}$ in the flame-sampled mass spectra.

As shown in Fig. 3(a) for the $i$-butene flame, all profiles reach their maxima at the same distance from the fuel outlet for the anticipated sequence $\mathrm{C}_{6} \mathrm{H}_{6} \rightarrow \mathrm{C}_{7} \mathrm{H}_{8} \rightarrow \mathrm{C}_{8} \mathrm{H}_{10} \rightarrow \mathrm{C}_{8} \mathrm{H}_{8} \rightarrow$ 
$\mathrm{C}_{8} \mathrm{H}_{6}$. Peaks for the sequence benzene $\rightarrow$ naphthalene $\rightarrow$ anthracene/phenanthrene appear also at the same distance [Fig. 3(b)]. Apparently, the limited thickness of the flame front and the spatial resolution of the sampling technique preclude obtaining a direct confirmation of this sequential growth and dehydrogenation/cyclization process from the location of the respective signal maximum. Finer microprobes and measurements under reduced pressure may allow for resolving such formation sequences in terms of peak positions in future experiments.

Further insights into the combustion chemistry are revealed when analyzing the signal intensities (i.e., the mole fractions) within the individual HAMA sequences starting at $m / z=78 \mathrm{u}$ (benzene), $m / z=102 \mathrm{u}$ (phenylacetylene), $m / z=104 \mathrm{u}$ (styrene), and the corresponding two-ring aromatics at $m / z=128 \mathrm{u}$ (naphthalene), $m / z=152 \mathrm{u}$ (acenaphthylene), and $m / z=154 \mathrm{u}$ (acenaphthene). Figure 5 provides the signal ratios from within HAMA sequences taken at $9.25 \mathrm{~mm}$ away from the fuel outlet, i.e., the flame position with strongest signals; specifically, it shows the ratio of a given signal at an $\mathrm{m} / \mathrm{z}$ value within a HAMA sequence to the signal at the sequence start. For example, Fig. 5 reports the signal ratios of $m / z=92 \mathrm{u}, 106 \mathrm{u}$, and $120 \mathrm{u}$ to $m / z=78 \mathrm{u}$. Interestingly, the observed ratios are the same for the flames of all three fuels.

Figure 5 demonstrates that the ratio between the first two members of each HAMA sequence is of the order of $0.15( \pm 0.05)$ when starting at $\mathrm{m} / \mathrm{z}=78 \mathrm{u}, 104 \mathrm{u}, 128 \mathrm{u}$, and $154 \mathrm{u}$. Interestingly, this ratio seems to be largely independent of the individual flame structure. As shown in the Supplementary Material, this ratio is also constant over the entire distance from the fuel outlet in which significant amounts of toluene and benzene were detected. The experimentally observed ratios for the three different flames over the sampled region were used to estimate the given uncertainty. Please note that this ratio is within the given uncertainties identical to the ratio of the toluene to benzene concentrations in many premixed flames of 
various fuels [50]; thus supporting our current analysis approach. A possible explanation for the observed repetitive nature of the same signal ratios over a wide mass range as shown in Fig. 5 is a pseudo first-order methyl addition reaction whose rate is independent of the methyl concentration and proportional to only the concentration of the aromatic reactant. It is apparent that the small differences in the peak flame temperature do not influence the signal ratios outside of the given experimental uncertainties. The observed constant ratios provides interesting insights into general features of flame-sampled mass spectra, which can eventually be used for modeling purposes when large isomeric PAHs are lumped together. However, the general validity should be tested for a larger variety of different flames and conditions, including the peak temperature.

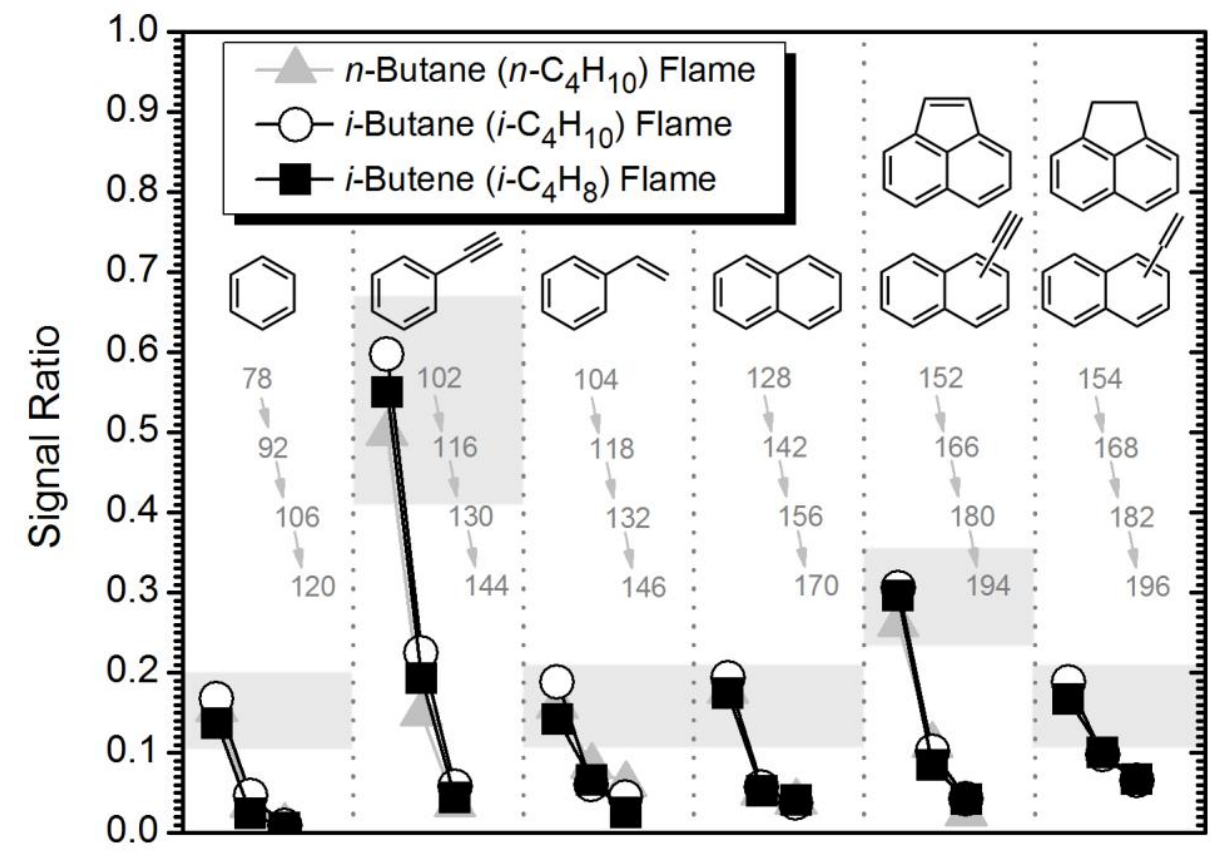

Figure 5: Signal ratios of various HAMA sequences starting at $m / z=78 \mathrm{u}\left(\mathrm{C}_{6} \mathrm{H}_{6}\right), 102 \mathrm{u}\left(\mathrm{C}_{8} \mathrm{H}_{6}\right)$, $104 \mathrm{u}\left(\mathrm{C}_{8} \mathrm{H}_{8}\right), 128 \mathrm{u}\left(\mathrm{C}_{10} \mathrm{H}_{8}\right), 152 \mathrm{u}\left(\mathrm{C}_{12} \mathrm{H}_{8}\right)$, and $154 \mathrm{u}\left(\mathrm{C}_{12} \mathrm{H}_{10}\right)$. For the first methyl addition step, the signal ratio is typically $\leq 0.2$. Obvious exceptions to this upper limit are the methyl addition to $m / z=102 \mathrm{u}$ (most likely phenylacetylene) and $m / z=152 \mathrm{u}$, which can be explained with the formation of five-membered ring structures. Estimated error bars are indicated as gray areas. Similar ratios were observed for all three flames. See text for more details. 
Significantly larger signal ratios of about $0.54( \pm 0.12)$ and $0.29( \pm 0.06)$, respectively, between the first two sequence members are observed when starting the HAMA sequence at $\mathrm{m} / \mathrm{z}$ $=102 \mathrm{u}$ and $\mathrm{m} / \mathrm{z}=152 \mathrm{u}$, a larger ratio meaning a higher efficiency in adding methyl groups. The likely explanation for these observations is the general preference to form thermodynamically more stable five-membered ring structures, i.e., indene, over alkyl-substituted aromatic ring structures containing three carbon atoms in the alkyl chain. This increased signal ratio does not necessarily imply that indene is formed through a HAMA sequence step - indeed, many other reactions might contribute to the formation of indene as well. However, methyl-addition to phenylacetylene, the intermediate at $\mathrm{m} / z=102 \mathrm{u}$, is likely to lead to tolylacetylene and/or 1phenyl-1-propyne. From Refs. [70, 71] it is known that the latter species and the ortho form of tolylacetylene can be converted into indene at high temperatures and/or catalyzed by $\mathrm{H}$-atoms:

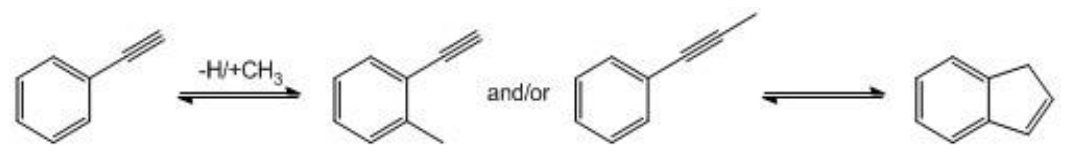

The importance of this proposed HAMA sequence step should be tested in flame kinetics and combustion chemistry modeling.

Other pathways potentially responsible for the observed enhanced signal ratio at $\mathrm{m} / \mathrm{z}=$ $116 \mathrm{u}$ versus $\mathrm{m} / \mathrm{z}=102 \mathrm{u}$ include the reaction of benzyl radicals with acetylene, which will be discussed below, and reactions of phenyl radicals with $\mathrm{C}_{3}$-species like allene and propargyl. At first glance, the flame-sampled mass spectra are not expected to allow for discrimination whether indene is built up from benzene via a sequential two-step methyl and acetylene-addition process or via the single-step addition of propargyl. However, we are able to distinguish between these two substantially different processes based on the following observations. 
As mentioned above, an intriguing feature in Fig. 5 is also the increased signal ratio for the HAMA sequence starting at the $m / z=152 \mathrm{u}$, which represents most likely a mixture of acenaphthylene and 1- and 2-ethynyl naphthalene isomers. If only the latter two isomers were present, one would expect a similar signal ratio of 0.6 as in the case of phenylacetylene $(\mathrm{m} / \mathrm{z}=$ $102 \mathrm{u}$ ) because reactions similar to (R6) can form the respective five-membered ring structures (1H-benz[e]indene and 1H-benz[f]indene):

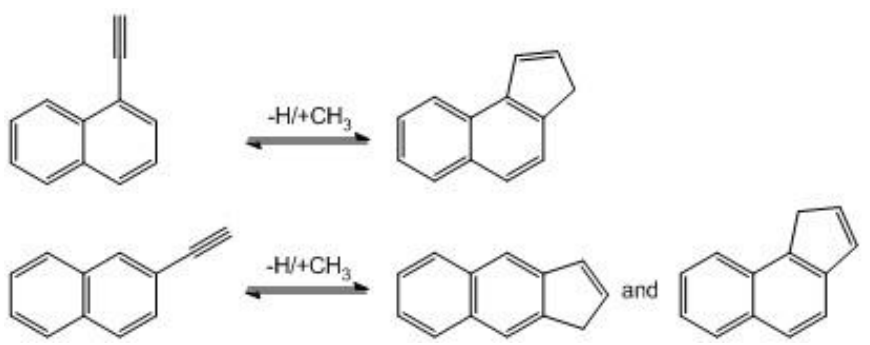

However, the observed ratio of the signals at $\mathrm{m} / \mathrm{z}=166 \mathrm{u}$ to $\mathrm{m} / \mathrm{z}=152 \mathrm{u}$ points towards the larger importance of a different reaction which again involves methyl-addition, thus leading to a lower ratio of $\sim 0.3$. The most likely explanation is a reaction of acenaphthylene, which is a stabilomer in the grid of Stein and Fahr [69] and has been unambiguously detected using the complementary gas chromatographic identification by Schenk et al. [49], with methyl to form methylacenaphthylene and eventually $1 \mathrm{H}$-phenalene:

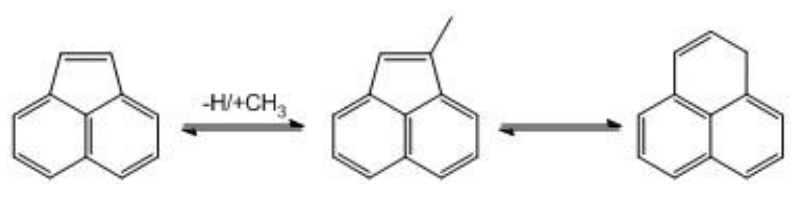

Based on the comparison of the expected ratio of 0.6 versus the actual value of 0.3 found here, it seems likely that $1 \mathrm{H}$-phenalene contributes significantly to the signal at $m / z=166 \mathrm{u}$.

Let us now consider that $\mathrm{C}_{13} \mathrm{H}_{10}$ intermediates of reactions (R7) and (R8) might also be formed through reaction of 1- or 2-naphthyl with propargyl radicals: 


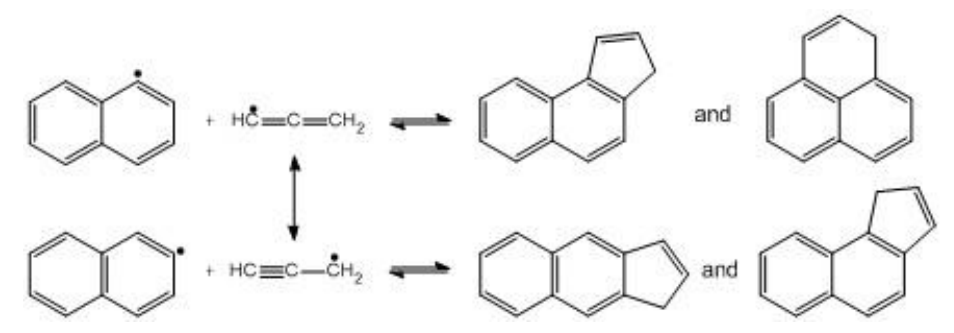

Should the latter reaction (R9) and the analogous formation of indene through phenyl radicals be of importance, it would be fair to assume that the ratio of the signal at $m / z=116 \mathrm{u}$ versus that at $m / z=78 \mathrm{u}$ should be similar to the ratio of the signal at $m / z=166 \mathrm{u}$ to that at $m / z=128 \mathrm{u}$. A quick analysis, however, shows that under our conditions this assumption does not hold (values of 0.06 versus 0.12 ) and therefore we can conclude that this one-step mechanism is likely not of major importance at this position of the flame. A two-step reaction scheme similar, but not identical, to the one discussed above had been proposed by Bittner and Howard [72]; here, we were able to draw a conclusion about the significance of such a two-step mechanism. The result about the reactions of propargyl radicals to form five-membered rings might be different when considering its reactions with benzyl-type radicals to form six-membered ring structures [43]. However, the mass spectra provide no further insights, thus highlighting potential opportunities for isomer-resolved studies if they should become feasible for this mass range in the future.

With regard to the products of reactions (R7) and (R8), we notice that the discussed $\mathrm{m} / \mathrm{z}=$ $166 \mathrm{u}$ isomers have a $\mathrm{sp}^{3}$-carbon atom of a $-\mathrm{CH}_{2}$ - group in common. Evidence for this structural feature, that can also be found in indene and fluorene [reaction (R2)], becomes visible in the mass spectra in the form of a large radical peak at $m / z=165$ u. As briefly discussed in Ref. [49], the $\mathrm{CH}_{2}$ group disturbs to some extent the resonance stabilization of the neutral intermediate, and the removal of an $\mathrm{H}$-atom from the $\mathrm{CH}_{2}$ group leads to very stable, fully resonantly stabilized radicals and consequently to larger signal compared to radicals from other PAHs. 
The last two methyl-radical reactions that should be discussed here are the bridging of the arm-chair configuration as found for example in biphenyl [reaction (R2)] and the methyl addition followed by a ring expansion [reaction (R3)]. For reaction (R2), the sequences are expected to start at $m / z=154 \mathrm{u}$ (biphenyl) and $m / z=178 \mathrm{u}$ (phenanthrene) and lead to $\mathrm{m} / \mathrm{z}=166 \mathrm{u}$ and $\mathrm{m} / \mathrm{z}=$ $190 \mathrm{u}$, respectively, but our flame-sampled mass spectra do not allow for an evaluation of the importance of this reaction class in the overall PAH formation process.

For reaction (R3), Fig. 4 suggests the presence of $m / z=130$ u that might be formed through a HAMA sequence starting at $m / z=116$ u (indene), followed by a dehydrogenation sequence $(-2 \mathrm{H})$ ending in naphthalene. These ring enlargement reactions have also been reported by Lifshitz et al. [73, 74], Jasper and Hansen [75], and Shukla et al. [39, 76]. A similar sequence is expected to convert five-membered ring structures at $m / z=166 \mathrm{u}$ species via $\mathrm{m} / \mathrm{z}=180 \mathrm{u}$ intermediates into anthracene and/or phenanthrene at $m / z=178 \mathrm{u}$. Even though these sequences are consistent with our mass spectra, the anticipated complexity of the chemistry precludes a reliable estimation of their importance. Their impact should be tested in detailed chemical kinetic modeling.

In summary, we can conclude that the importance of the first step of the HAMA sequence stays constant over the entire range analyzed here. HAMA sequences might be more important when ethynyl (-CCH) side chains are present because that eventually allows for the formation of preferred five-membered ring structures. Although the present study provides only a limited number of data points, it appears that methyl-addition becomes less important for larger alkenylsubstituted PAHs. This observation, which is largely in agreement with Homann [77] who concluded that "methyl radicals do not contribute to the formation of large molecules," is probably a consequence of fewer $\mathrm{CCH}$ groups present in these molecules, as they have the 
tendency to be present as five- or six-membered ring-structures instead. For example, as discussed above, acenaphthylene, a stabilomer according to Stein and Fahr [69], is likely to be present in higher concentrations than the isomeric 1- and 2-ethynyl naphthalene at $m / z=152 \mathrm{u}$; i.e., the ethynyl group preferably bridges the zig-zag CCC structure in naphthalene to form a five-membered ring.

\section{(c) $\mathrm{H}$-Abstraction- $\mathrm{C}_{2} \mathrm{H}_{2}$ (Acetylene)-Addition Sequence}

In addition to the reoccurring intervals of 14 mass units in the observed flame-sampled mass spectra discussed in the last section, we now investigate the sequences in which the peaks are separated by 24 mass units. Given the conditions from which the mass spectra were sampled, it is likely that these sequences can be explained by repetitive $\mathrm{H}$-abstraction- $\mathrm{C}_{2} \mathrm{H}_{2}$-addition reactions. We will refer to this sequence as "HACA sequence" in order to avoid confusion with the "HACA mechanism" that was introduced by Wang and Frenklach $[4,26,78]$. These authors originally intended to describe a specific reaction set of $\mathrm{H}$-abstraction and acetylene-addition reactions that convert, for example, benzene into naphthalene and naphthalene into anthracene/phenanthrene, etc. The HACA sequences observed in the mass spectra and discussed here are only individual consecutive reactions and not a complete set of ring-forming reactions, i.e., the "HACA mechanism". Our data allows for assessment of the importance of specific Habstraction $-\mathrm{C}_{2} \mathrm{H}_{2}$ addition reactions, but is not enabling an evaluation of the importance of the entire "HACA mechanism".

A first consecutive HACA sequence in the mass spectra starts at $m / z=78 \mathrm{u}$ and continues at $m / z=102 \mathrm{u}, 126 \mathrm{u}$, and $150 \mathrm{u}$, see also Fig. 6. For $m / z=78 \mathrm{u}$ and $102 \mathrm{u}$, benzene and phenylacetylene are the well accepted combustion intermediates, while there are more candidates 
for $m / z=126 \mathrm{u}$ and $150 \mathrm{u}$. According to reaction (R10) and indicated in Fig. 6, it is plausible that the intermediates are the di- and tri-ethynyl benzenes that can be formed via additional HACA sequence steps starting at phenylacetylene and involving any of the di-ethynyl benzenes, respectively:

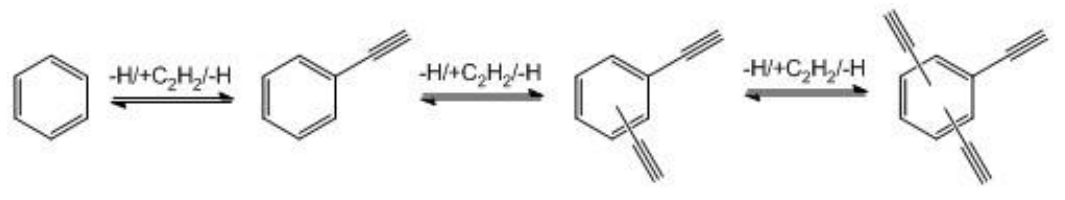

Unlike the HAMA sequences in which the formation of an alkyl chain is expected to be preferred over the formation of a di-methyl or tri-methyl derivative of the aromatic ring, it is anticipated that HACA sequences such as (R10) are more likely to occur from and at the aromatic ring side to form the corresponding di- and tri-ethynyl structures (preferably in the ortho- or para-position based on the stability of the respective radicals [79]). This difference in product distribution compared to the $\mathrm{CH}_{3}$-addition reaction is likely a consequence of the lower stability of the corresponding $\mathrm{C}_{6} \mathrm{H}_{5} \mathrm{CC}$ vs. the $\mathrm{C}_{6} \mathrm{H}_{4} \mathrm{CCH}$ and the $\mathrm{C}_{7} \mathrm{H}_{7}$ (benzyl) radicals that makes it unlikely to add another ethynyl group to the side chain [79, 80]. Parker et al. [81] claimed that under "combustion-like" conditions, a second hydrogen abstraction from phenylacetylene at the ring can be ruled out; however, our findings are not in agreement with their conclusions. For any ortho-di-ethynyl benzene, it is conceivable that through subsequent $\mathrm{H}$-addition and cyclization steps, the corresponding two-ring species (in this case naphthyl radical) is formed. This reaction, which is similar to reactions described for example by Richter and Howard [6] and Gu et al. [80], is included in many chemical kinetic modeling efforts. 


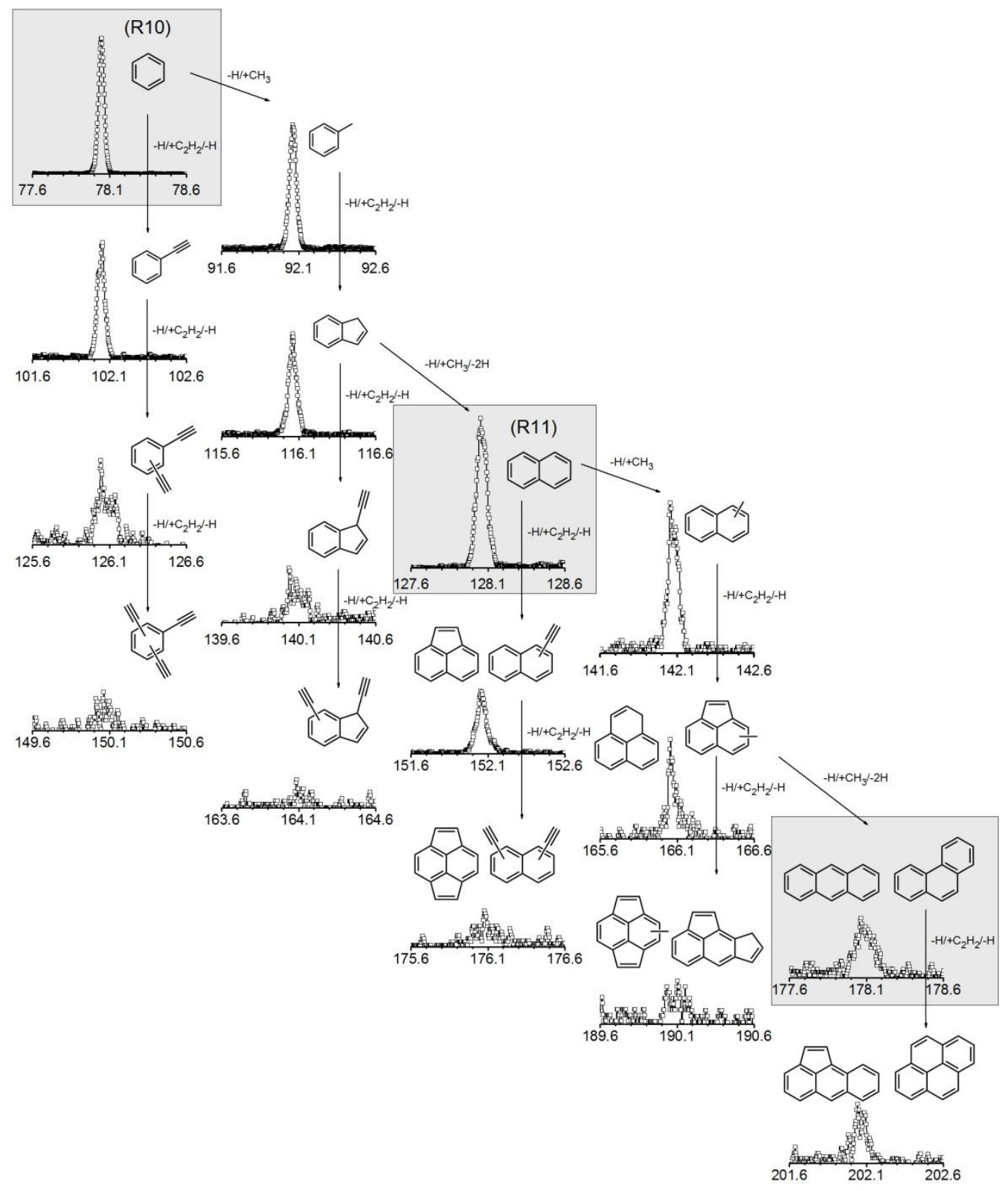

Figure 6: Signal of flame-sampled mass spectra from the $i$-butene flame. Repetitive $H A C A$ sequences start at $m / z=78 \mathrm{u}, 92 \mathrm{u}, 128 \mathrm{u}, 142 \mathrm{u}$, and $178 \mathrm{u}$. A maximum of two isomeric structures are shown, however we do not wish to indicate that only these species are present. The arrows indicate how these species (or their isomers) are likely to be connected with one another. Single-, double-, and triple-ring aromatic species are $m / z=78,128$, and $178 \mathrm{u}$ are highlighted as well as reactions (R10) and (R11) that are discussed in more detail in the text. 
A similar HACA sequence of mass peaks at $m / z=128 \mathrm{u}, 152 \mathrm{u}$, and $176 \mathrm{u}$ can easily be recognized in the flame-sampled mass spectra, and typically the signals are assigned to naphthalene, acenaphthylene, and pyracylene formed via reaction (R11):

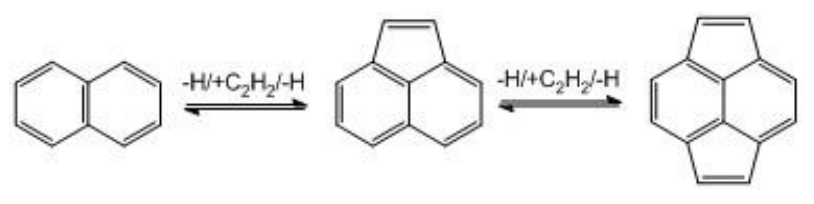

We note that signal at $m / z=200 \mathrm{u}$ is already below the detection limit, thus indicating that this HACA sequence adding to naphthalene is inefficient to produce larger PAHs because it actually stops further growth. A likely explanation of this observation is found in the theoretical predictions of Kislov et al. [36] who showed that repetitive acetylene addition to naphthalene is more likely to form five-membered ring structures like acenaphthylene and pyracyclene than anthracene and phenanthrene. However, similar to the benzene reaction (R10), the presence of the mono- and di-substituted ethynyl naphthalenes cannot be ruled out (see also Fig. 6), but would not explain the observed stop in the HACA sequence. Ultimately, the reactions of these ethynyl-substituted aromatic species [for example reaction (R7)] lead to a different intermediate pool than indicated in reaction (R11).

Besides benzene and naphthalene, also their methyl-substituted equivalents, i.e., toluene and methyl naphthalene, can serve as starting intermediates for the discussed HACA sequences, leading to sequences at $m / z=92 \mathrm{u}, 116 \mathrm{u}, 140 \mathrm{u}, 164 \mathrm{u}$, and $m / z=142 \mathrm{u}, 166 \mathrm{u}$, and $190 \mathrm{u}$, respectively. A simplified picture of how these species are connected via various $\mathrm{CH}_{3}$ and $\mathrm{C}_{2} \mathrm{H}_{2}$ addition reactions is shown in Fig. 6. Again, we have to keep in mind that many other reactions can occur as well and that for such large intermediates, it is impossible to unambiguously assign molecular structures. The sequence starting at $m / z=104 \mathrm{u}$ (styrene) is likely to lead immediately 
to naphthalene following the first $\mathrm{H}$-abstraction and $\mathrm{C}_{2} \mathrm{H}_{2}$ addition reactions and is therefore not included in the discussions.

In order to gain further insights into this observed HACA sequences, a similar analysis strategy was chosen as for the HAMA sequences. In essence, we compare signal ratios in the sequences starting at $m / z=78 \mathrm{u}, 92 \mathrm{u}, 128 \mathrm{u}, 142 \mathrm{u}$, and $178 \mathrm{u}$. The results are shown in Fig. 7. As for the HAMA sequences, it seems remarkable that the three flames investigated here behave in a similar way, i.e., similar signal ratios have been observed for the various flames studied in this work. Although the explanation for this behavior is not entirely clear at this point, a possible explanation might be, similar to the HAMA case, a pseudo first-order reaction whose overall rate depends on the aromatic reactant concentration only. The slightly larger differences in the ratios between the flames compared to the ratios determined for the HAMA sequences might indicate that this reaction is more temperature sensitive.

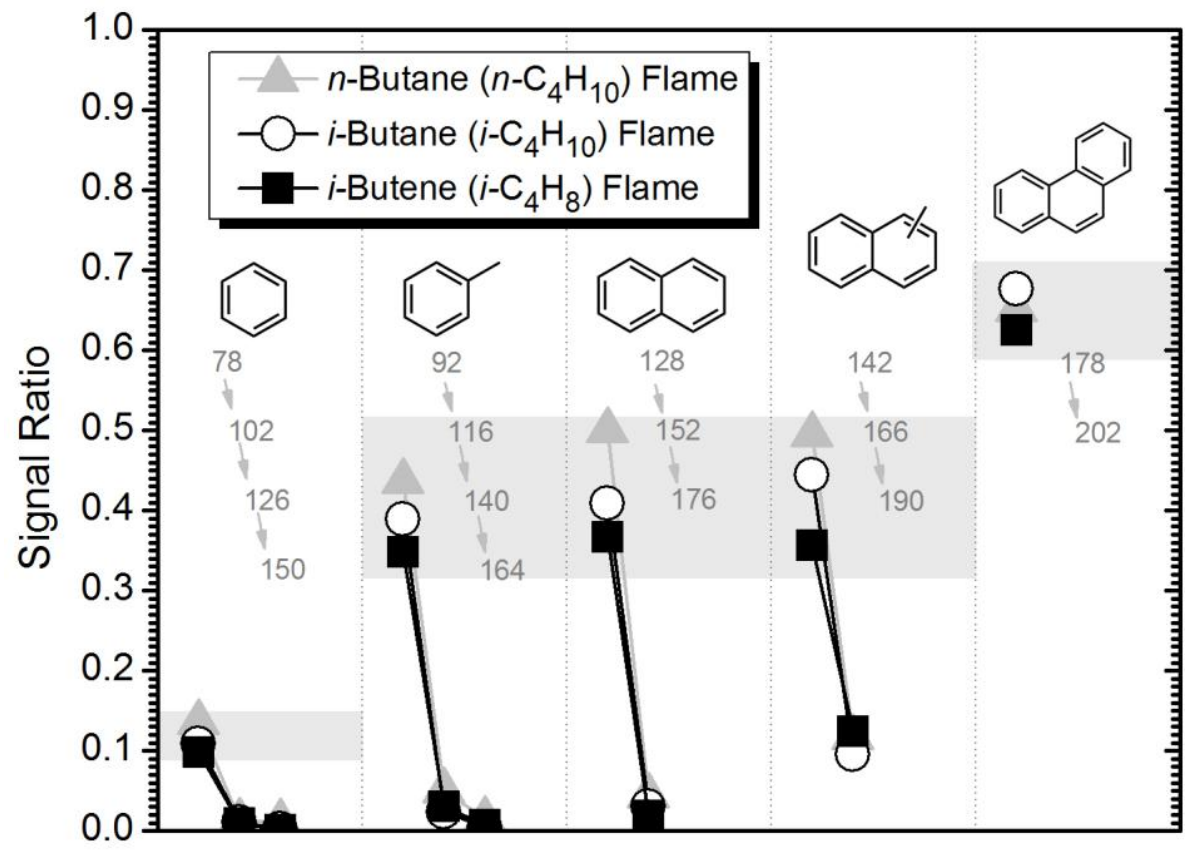

Figure 7: Signal ratios of various $\mathrm{H}$-abstraction acetylene-addition sequences starting at $\mathrm{m} / \mathrm{z}=$ $78 \mathrm{u}\left(\mathrm{C}_{6} \mathrm{H}_{6}\right), 92 \mathrm{u}\left(\mathrm{C}_{7} \mathrm{H}_{8}\right), 128 \mathrm{u}\left(\mathrm{C}_{10} \mathrm{H}_{8}\right), 142 \mathrm{u}\left(\mathrm{C}_{11} \mathrm{H}_{10}\right)$, and $178 \mathrm{u}\left(\mathrm{C}_{14} \mathrm{H}_{10}\right)$. Acetylene-addition reactions are more likely to occur when five- and/or six-membered ring structures can be formed, i.e., toluene $\rightarrow$ indene, naphthalene $\rightarrow$ acenapthylene, etc. Significant is the ratio between $m / z=$ 
$178 \mathrm{u}$ (most likely anthracene and phenanthrene) and $\mathrm{m} / \mathrm{z}=202$ (including pyrene). The estimated errors for the ratios of the first step in each sequence are indicated by the gray box. See text for more details.

As mentioned above for the HAMA sequences: The fact that the signal ratios in flamesampled mass spectra seem to be constant over a larger mass range within given moleculargrowth reaction sequences provides an interesting tool for interpreting some general features of such mass spectra, which can eventually be used for modeling purposes. Nevertheless, the broader applicability should be tested for a larger variety of different flames and conditions.

Comparing Fig. 5 and Fig. 7, we notice (in their first columns) that the phenylacetyleneto-benzene signal ratio with $0.12( \pm 0.03)$ is significantly smaller than the ratios of the signals at $\mathrm{m} / \mathrm{z}=92$ to $\mathrm{m} / \mathrm{z}=78$ of $\sim 0.17$, maybe indicating that acetylene addition is less efficient than the first HAMA sequence step or that there are other pathways leading to toluene. Starting at naphthalene, this situation seems inverted, that is, the first step in the HACA sequence seems with $0.42( \pm 0.1)$ more efficient than forming methyl naphthalene corresponding to a ratio of $\sim 0.2$. This result might be a consequence of the thermal stability of the acenaphthylene isomer expected at $m / z=152 \mathrm{u}[$ reaction $(\mathrm{R} 11)]$.

Comparing the HACA sequence steps from various starting intermediates, it can be seen from Fig. 7 that acetylene-addition reactions generally are more likely to occur when five- or sixmembered rings can be formed. For example, the signal ratio of $m / z=116 \mathrm{u}$ (indene) to $\mathrm{m} / \mathrm{z}=$ $92 \mathrm{u}$ (toluene) is with $\sim 0.4$ about four times larger than the signal ratio (of $\sim 0.1$ ) of $\mathrm{m} / \mathrm{z}=102 \mathrm{u}$ (phenylacetylene) to $m / z=78 \mathrm{u}$ (benzene). The same argument of the stability of five- and sixmembered ring structures could be made to explain the signal ratios observed for the sequences starting at $m / z=128 \mathrm{u}$ (naphthalene) and $m / z=142 \mathrm{u}$ (methyl naphthalene), both of the order of 
0.4. Possible reactions leading to indene-like rings and/or $1 \mathrm{H}$-phenalene are summarized in reaction $(\mathrm{R} 12)$ :
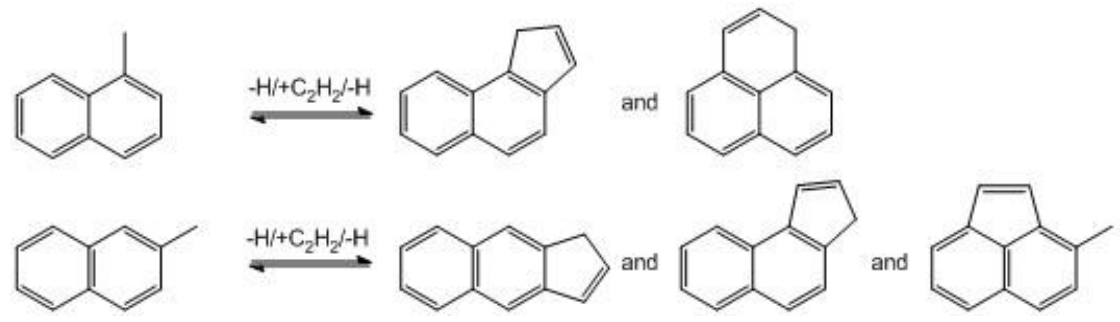

It is intriguing to inspect the formation of $m / z=202 \mathrm{u}$, typically assumed as pyrene, the dimerization of which has been postulated as a first step to soot inception [82-85]. The ratio of $m / z=202 \mathrm{u}$ to $\mathrm{m} / \mathrm{z}=178 \mathrm{u}$, of the order of $0.65( \pm 0.06)$, is even larger than those discussed before, probably indicating a high stability of the $m / z=202 \mathrm{u}$ isomer. If only the stabilomer anthracene would be present at $m / z=178 \mathrm{u}$, a similar signal ratio (of $\sim 0.4$ ) of $\mathrm{m} / \mathrm{z}=202 \mathrm{u}$ to $\mathrm{m} / \mathrm{z}$ $=178 \mathrm{u}$ could be assumed as in the case of the sequence starting at naphthalene. The observed larger signal ratio might be explained by a preferred bridging of the arm-chair CCCC configuration in phenanthrene, which is initiated by a HACA sequence step and then followed by cyclization:

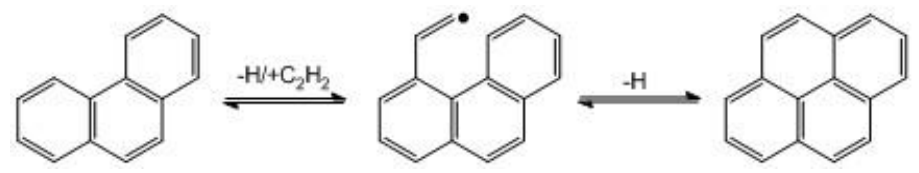

The last $\mathrm{C}_{2} \mathrm{H}_{2}$ addition reaction that should be discussed here is the ring-enlargement reaction that converts cyclopentadienyl-like structures into benzyl-like structures, as described by Cavallotti and co-workers $[20,86,87]$. For example, indene could react via a HACA sequence step to methyl naphthalene. The fact that the ratio of the signals at $m / z=142 \mathrm{u}$ to $\mathrm{m} / \mathrm{z}=128 \mathrm{u}$ is the same as for the HAMA sequences starting at $m / z=78 \mathrm{u}, 104 \mathrm{u}$, and $154 \mathrm{u}$ (see Fig. 3), indicates that no additional reactions are likely to contribute towards methyl naphthalene. We 
therefore conclude that under the conditions in the flames presented here, these ring-enlargement reactions are not significantly contributing towards $\mathrm{PAH}$ growth.

\section{Summary and Conclusions}

In this paper an empirical analysis is described that allows for drawing mechanistic conclusions based on an analysis of repetitive hydrogen-abstraction and methyl- and acetylene addition reactions. This approach is based on a compromise between the lack of chemically detailed, i.e., isomer-resolved, information and current experimental and modeling capabilities. In this work we have investigated experimentally such sequences in flame-sampled mass spectra in the range of $m / z=78 \mathrm{u}$ to $\mathrm{m} / \mathrm{z}=202 \mathrm{u}$, typically assumed to be the region between the first aromatic ring, mostly identified as benzene, and the end of the molecular growth region preceding soot nucleation, typically assumed to include pyrene whose dimerization is thought to represent a crucial connection between molecular mass growth and particle inception. These mass spectra were taken from the center-line of atmospheric-pressure opposed-flow diffusion flames of $n$-butane, $i$-butane, and $i$-butene. A graphical summary of the repetitive pathways investigated here is presented in Fig. 8, in which $+14 \mathrm{u}$ and $+24 \mathrm{u}$ sequences are shown together with the dehydrogenation $(-2 \mathrm{u})$ reactions that connect these former steps. As can be seen from this Figure, numerous features of the mass spectrum can be explained and different pathways that start at $m / z=78 \mathrm{u}\left(\mathrm{C}_{6} \mathrm{H}_{6}\right)$ can lead to $m / z=202 \mathrm{u}\left(\mathrm{C}_{16} \mathrm{H}_{10}\right)$. 


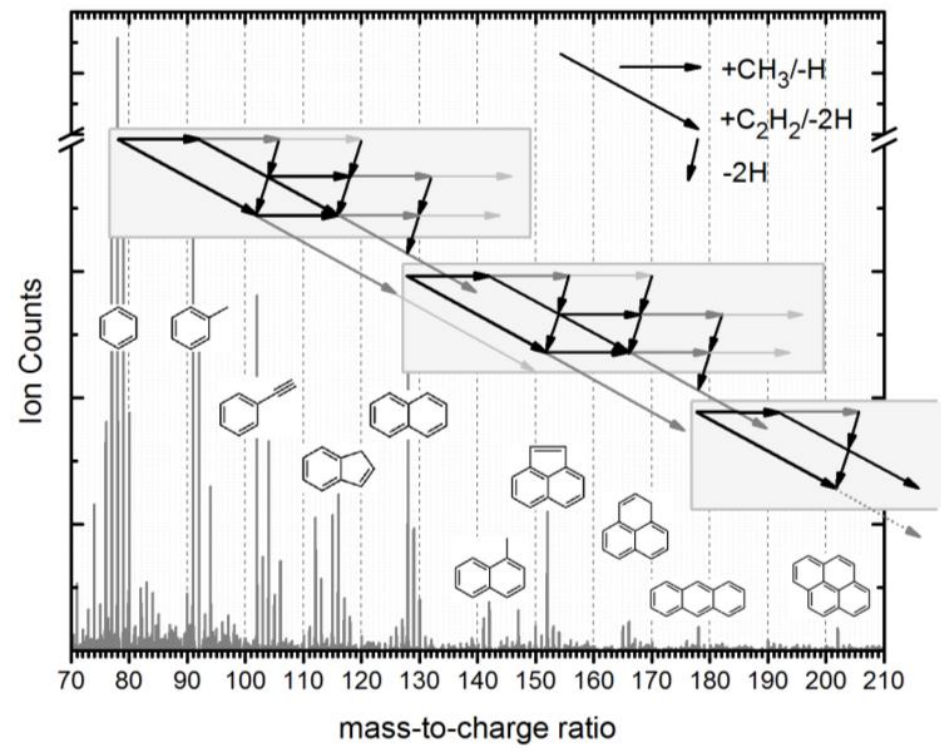

Figure 8: A graphical summary of the repetitive pathways discussed in this work. Flamesampled mass spectra in the range from $m / z=78$ u to $m / z=202$ u can in large be explained by repetitive sequences of $\mathrm{H}$-abstraction and $\mathrm{CH}_{3}-$ and $\mathrm{C}_{2} \mathrm{H}_{2}$-addition reactions. Dehydrogenation and cyclization processes occur whenever possible, preferably to form five- and six-membered ring structures. The grey boxes indicate sequences starting from one- (benzene), two(naphthalene), and three- (anthracene) ring systems.

Despite the simplicity of the reaction network discussed here, it seems plausible that a number of different isomers might contribute to $\mathrm{m} / \mathrm{z}=202 \mathrm{u}$. Just assuming anthracene and phenanthrene to be contributors at $m / z=178 \mathrm{u}$, the discussed methyl and acetylene addition sequences (followed by dehydrogenation and ring-closures) are likely to lead to the different isomers at $m / z=202 \mathrm{u}$ that are shown in Fig. 9. Therefore, this work adds doubt on the general validity of the assumption that pyrene dimerization is the dominant particle inception pathway $[84,88]$.

The reported constant signal ratios over a wide mass range within the discussed HAMA and $H A C A$ sequences present interesting information that can be used to understand general trends in PAH signal intensities in flame-sampled mass spectra, and may potentially represent 
valuable validation targets. Interestingly the signal ratios for the first step in the HAMA sequence match, within the given uncertainties, the toluene-to-benzene ratio measured in a variety of different low-pressure premixed flames [50], thus adding confidence to the present analysis of quantitative signal ratios.

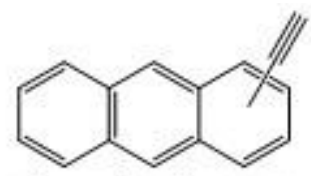

ethynyl anthracene

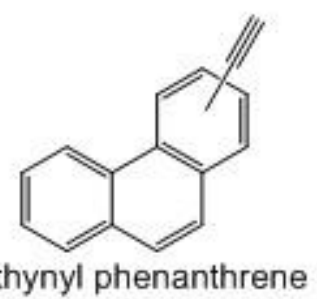

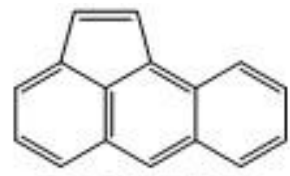

aceanthrylene

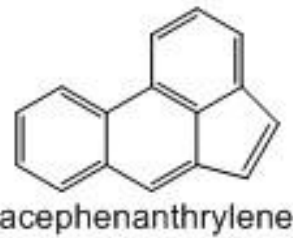

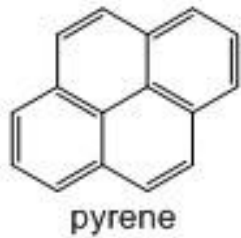

pyrene

Figure 9: Expected isomers at $m / z=202 \mathrm{u}\left(\mathrm{C}_{16} \mathrm{H}_{10}\right)$ that can be formed through the methyl- and acetylene-addition sequences (followed by dehydrogenation and/or cyclization) discussed in this paper when starting at $m / z=178 \mathrm{u}$ (anthracene and phenanthrene).

From the measured signal ratios, we were also capable of extracting chemical information: The methyl addition reactions (HAMA sequences) tend to form alkyl side chains, but the dominance of the $-2 \mathrm{u}$ peaks indicates the formation of more stable products with $-\mathrm{C}_{2} \mathrm{H}_{3}$ or $-\mathrm{C}_{2} \mathrm{H}$ side groups or the formation of externally fused five-membered ring PAHs. The corresponding acetylene-addition reactions (HACA sequences) have been found to be important, especially for reactants larger than benzene. This importance is probably based on the preference of the reactions leading to five- and or six-membered ring structures. That makes $\mathrm{C}_{2} \mathrm{H}_{2}$ addition reactions more efficient than methyl radical reactions to form larger molecules. Acetylene addition is typically more important than methyl addition by about a factor of two, under the given conditions. 
We have not observed any fuel-structure dependence of the signal ratios in the covered range of the flame-sampled mass spectra but it is likely that the ratios depend to some extent on the flame temperature. These observations might not be generalized before obtaining more insights from comparisons of more different flame conditions (including different fuels classes and temperatures) and from flame chemistry modeling. For example, we expect that a different toluene-to-benzene ratio will be detected in flames in which toluene might be formed preferentially through fuel-structure specific reactions as in methylcyclohexane [89] or 2-methyl2-butene flames [50]. Given the current knowledge of PAH formation in combustion environments, it is not expected that such an elementary approach as shown here can explain the details of the entire PAH formation chemistry. However, interestingly, the similarity between the spectra suggests that it might be possible to analyze the flame-sampling mass spectra without knowing the detailed isomer-resolved chemistry. Future work should focus on identifying correlations between PAH molecules similar to the ones presented here, but involving different precursor molecules.

\section{Acknowledgements}

The authors thank H. Waterbör, Bielefeld University, for expert technical assistance. NH acknowledges funding through the Alexander von Humboldt-Foundation and through the Division of Chemical Sciences, Geosciences, and Biosciences, the Office of Basic Energy Sciences, the US Department of Energy. Sandia is a multiprogram laboratory operated by Sandia Corp., a Lockheed Martin Co., for the National Nuclear Security Administration under Contract DE-AC04-94-AL85000. 


\section{References:}

[1] H. Bockhorn; A. D'Anna; A.F. Sarofim; H. Wang (Ed.), Combustion generated fine carbonaceous particles, KIT Scientific Publishing, Karlsruhe, 2009.

[2] F. Battin-Leclerc; J.M. Simmie; E. Blurock (Ed.), Cleaner combustion, Springer, London, 2013.

[3] P. Desgroux; X. Mercier; K.A. Thomson, Study of the formation of soot and its precursors in flames using optical diagnostics. Proc. Combust. Inst. 34 (2013) 17131738.

[4] H. Wang, Formation of nascent soot and other condensed-phase materials in flames. Proc. Combust. Inst. 33 (2011) 41-67.

[5] C.S. McEnally; L.D. Pfefferle; B. Atakan; K. Kohse-Höinghaus, Studies of aromatic hydrocarbon formation mechanisms in flames: Progress towards closing the fuel gap. Progr. Energy Combust. Sci. 32 (3) (2006) 247-294.

[6] H. Richter; J.B. Howard, Formation of polycyclic aromatic hydrocarbons and their growth to soot - a review of chemical reaction pathways. Prog. Energy Combust. Sci. 26 (4-6) (2000) 565-608.

[7] A.J. Cohen, Outdoor air pollution and lung cancer. Environ. Health Perspect. 108 (4) (2000) 743-750.

[8] J.S. Gaffney; N.A. Marley, The impacts of combustion emissions on air quality and climate - From coal to biofuels and beyond. Atmos. Environ. 43 (1) (2009) 23-36.

[9] H.D. Kan; R.J. Chen; S.L. Tong, Ambient air pollution, climate change, and population health in China. Environ. Int. 42 (2012) 10-19.

[10] J. Lewtas, Air pollution combustion emissions: Characterization of causative agents and mechanisms associated with cancer, reproductive, and cardiovascular effects. Mutat. Res. Rev. Mutat. 636 (1-3) (2007) 95-133.

[11] J.S. Lighty; J.M. Veranth; A.F. Sarofim, Combustion aerosols: Factors governing their size and composition and implications to human health. J. Air Waste Manage. Assoc. 50 (9) (2000) 1565-1618.

[12] K. Ravindra; R. Sokhi; R. Van Grieken, Atmospheric polycyclic aromatic hydrocarbons: Source attribution, emission factors and regulation. Atmos. Environ. 42 (13) (2008) 2895-2921.

[13] N. Hansen; J.A. Miller; S.J. Klippenstein; P.R. Westmoreland; K. Kohse-Höinghaus, Exploring formation pathways of aromatic compounds in laboratory-based model flames of aliphatic fuels. Combust. Expl. Shock Waves 48 (5) (2012) 508-515.

[14] J.A. Miller; M.J. Pilling; J. Troe, Unravelling combustion mechanisms through a quantitative understanding of elementary reactions. Proc. Combust. Inst. 30 (1) (2005) 43-88.

[15] N. Hansen; T. Kasper; S.J. Klippenstein; P.R. Westmoreland; M.E. Law; C.A. Taatjes; K. Kohse-Höinghaus; J. Wang; T.A. Cool, Initial steps of aromatic ring formation in a laminar premixed fuel-rich cyclopentene flame. J. Phys. Chem. A 111 (19) (2007) 40814092.

[16] N. Hansen; W. Li; M.E. Law; T. Kasper; P.R. Westmoreland; B. Yang; T.A. Cool; A. Lucassen, The importance of fuel dissociation and propargyl plus allyl association for the formation of benzene in a fuel-rich 1-hexene flame. Phys. Chem. Chem. Phys. 12 (38) (2010) 12112-12122. 
[17] N. Hansen; J.A. Miller; T. Kasper; K. Kohse-Höinghaus; P.R. Westmoreland; J. Wang; T.A. Cool, Benzene formation in premixed fuel-rich 1,3-butadiene flames. Proc. Combust. Inst. 32 (2009) 623-630.

[18] N. Hansen; J.A. Miller; P.R. Westmoreland; T. Kasper; K. Kohse-Höinghaus; J. Wang; T.A. Cool, Isomer-specific combustion chemistry in allene and propyne flames. Combust. Flame 156 (11) (2009) 2153-2164.

[19] A. Nawdiyal; N. Hansen; T. Zeuch; L. Seidel; F. Mauss, Experimental and modelling study of speciation and benzene formation pathways in premixed 1-hexene flames. Proc. Combust. Inst. 35 (2015) 325-332.

[20] S. Fascella; C. Cavallotti; R. Rota; S. Carra, The peculiar kinetics of the reaction between acetylene and the cyclopentadienyl radical. J. Phys. Chem. A 109 (33) (2005) 75467557.

[21] C. Cavallotti; D. Polino, On the kinetics of the $\mathrm{C}_{5} \mathrm{H}_{5}+\mathrm{C}_{5} \mathrm{H}_{5}$ reaction. Proc. Combust. Inst. 34 (2013) 557-564.

[22] N. Hansen; S.J. Klippenstein; C.A. Taatjes; J.A. Miller; J. Wang; T.A. Cool; B. Yang; R. Yang; L.X. Wei; C.Q. Huang; F. Qi; M.E. Law; P.R. Westmoreland, Identification and chemistry of $\mathrm{C}_{4} \mathrm{H}_{3}$ and $\mathrm{C}_{4} \mathrm{H}_{5}$ isomers in fuel-rich flames. J. Phys. Chem. A 110 (10) (2006) 3670-3678.

[23] M. Frenklach; J. Warnatz, Detailed modeling of PAH profiles in a sooting low-pressure acetylene flame. Combust. Sci. Technol. 51 (4-6) (1987) 265-283.

[24] M.B. Colket, The pyrolysis of acetylene and vinylacetylene in a single-pulse shock tube. Proc. Combust. Inst. 21 (1) (1986) 851-864.

[25] N. Hansen; T. Kasper; B. Yang; T.A. Cool; W. Li; P.R. Westmoreland; P. Oßwald; K. Kohse-Höinghaus, Fuel-structure dependence of benzene formation processes in premixed flames fueled by $\mathrm{C}_{6} \mathrm{H}_{12}$ isomers. Proc. Combust. Inst. 33 (2011) 585-592.

[26] M. Frenklach, Reaction mechanism of soot formation in flames. Phys. Chem. Chem. Phys. 4 (11) (2002) 2028-2037.

[27] H. Wang; M. Frenklach, A detailed kinetic modeling study of aromatics formation in laminar premixed acetylene and ethylene flames. Combust. Flame 110 (1-2) (1997) 173221.

[28] J. Appel; H. Bockhorn; M. Frenklach, Kinetic modeling of soot formation with detailed chemistry and physics: Laminar premixed flames of $C_{2}$ hydrocarbons. Combust. Flame $121(1-2)(2000)$ 122-136.

[29] J.T. McKinnon; J.B. Howard, The roles of PAH and acetylene in soot nucleation and growth. Proc. Combust. Inst. 24 (1) (1992) 965-971.

[30] A. D'Anna; A. Violi, A kinetic model for the formation of aromatic hydrocarbons in premixed laminar flames. Proc. Combust. Inst. 27 (1) (1998) 425-433.

[31] A. Keller; R. Kovacs; K.H. Homann, Large molecules, ions, radicals and small soot particles in fuel-rich hydrocarbon flames. Part IV. Large polycyclic aromatic hydrocarbons and their radicals in a fuel-rich benzene-oxygen flame. Phys. Chem. Chem. Phys. 2 (8) (2000) 1667-1675.

[32] K.O. Johansson; J.Y.W. Lai; S.A. Skeen; D.M. Popolan-Vaida; K.R. Wilson; N. Hansen; A. Violi; H.A. Michelsen, Soot precursor formation and limitations of the stabilomer grid. Proc. Combust. Inst. 35 (2015) 1819-1826. 
[33] A. Raj; P.L.W. Man; T.S. Totton; M. Sander; R.A. Shirley; M. Kraft, New polycyclic aromatic hydrocarbon $(\mathrm{PAH})$ surface processes to improve the model prediction of the composition of combustion-generated PAHs and soot. Carbon 48 (2) (2010) 319-332.

[34] J.Y.W. Lai; P. Elvati; A. Violi, Stochastic atomistic simulation of polycyclic aromatic hydrocarbon growth in combustion. Phys. Chem. Chem. Phys. 16 (17) (2014) 7969-7979.

[35] K. Moshammer; L. Seidel; Y. Wang; H. Selim; S.M. Sarathy; F. Mauss; N. Hansen, Aromatic ring formation in opposed-flow diffusive 1,3-butadiene flames. Proc. Combust. Inst. submitted (2015).

[36] V.V. Kislov; A.I. Sadovnikov; A.M. Mebel, Formation mechanism of polycyclic aromatic hydrocarbons beyond the second aromatic ring. J. Phys. Chem. A 117 (23) (2013) 4794-4816.

[37] M. Panariello; B. Apicella; M. Armenante; A. Bruno; A. Ciajolo; N. Spinelli, Analysis of polycyclic aromatic hydrocarbon sequences in a premixed laminar flame by on-line timeof-flight mass spectrometry. Rapid Commun. Mass Spectrom. 22 (4) (2008) 573-581.

[38] B. Shukla; M. Koshi, Comparative study on the growth mechanisms of PAHs. Combust. Flame 158 (2) (2011) 369-375.

[39] B. Shukla; A. Miyoshi; M. Koshi, Role of methyl radicals in the growth of PAHs. J. Am. Soc. Mass Spectrom. 21 (4) (2010) 534-544.

[40] S.S. Yoon; D.H. Anh; S.H. Chung, Synergistic effect of mixing dimethyl ether with methane, ethane, propane, and ethylene fuels on polycyclic aromatic hydrocarbon and soot formation. Combust. Flame 154 (3) (2008) 368-377.

[41] S.S. Yoon; S.M. Lee; S.H. Chung, Effect of mixing methane, ethane, propane, and propene on the synergistic effect of PAH and soot formation in ethylene-base counterflow diffusion flames. Proc. Combust. Inst. 30 (2005) 1417-1424.

[42] B. Shukla; M. Koshi, A novel route for PAH growth in HACA based mechanisms. Combust. Flame 159 (12) (2012) 3589-3596.

[43] P. Lindstedt; L. Maurice; M. Meyer, Thermodynamic and kinetic issues in the formation and oxidation of aromatic species. Faraday Discuss. 119 (2001) 409-432.

[44] A. Raj; M.J. Al Rashidi; S.H. Chung; S.M. Sarathy, PAH growth initiated by propargyl addition: Mechanism development and computational kinetics. J. Phys. Chem. A 118 (16) (2014) 2865-2885.

[45] A. Raj; I.D.C. Prada; A.A. Amer; S.H. Chung, A reaction mechanism for gasoline surrogate fuels for large polycyclic aromatic hydrocarbons. Combust. Flame 159 (2) (2012) 500-515.

[46] D.H. Kim; J.A. Mulholland; D. Wang; A. Violi, Pyrolytic hydrocarbon growth from cyclopentadiene. J. Phys. Chem. A 114 (47) (2010) 12411-12416.

[47] B. Shukla; M. Koshi, A highly efficient growth mechanism of polycyclic aromatic hydrocarbons. Phys. Chem. Chem. Phys. 12 (10) (2010) 2427-2437.

[48] H. Richter; S. Granata; W.H. Green; J.B. Howard, Detailed modeling of PAH and soot formation in a laminar premixed benzene/oxygen/argon low-pressure flame. Proc. Combust. Inst. 30 (2005) 1397-1405.

[49] M. Schenk; N. Hansen; H. Vieker; A. Beyer; A. Golzhäuser; K. Kohse-Höinghaus, PAH formation and soot morphology in flames of $C_{4}$ fuels. Proc. Combust. Inst. 35 (2015) 1761-1769. 
[50] L. Ruwe; K. Moshammer; N. Hansen; K. Kohse-Höinghaus, Consumption and hydrocarbon growth processes in a 2-methyl-2-butene flame. Combust. Flame in press (2016).

[51] M. Schenk; L. Leon; K. Moshammer; P. Oßwald; T. Zeuch; L. Seidel; F. Mauß; K. Kohse-Höinghaus, Detailed mass spectrometric and modeling study of isomeric butene flames. Combust. Flame 160 (3) (2013) 487-503.

[52] P. Oßwald; K. Kohse-Höinghaus; U. Struckmeier; T. Zeuch; L. Seidel; L. Leon; F. Mauss, Combustion chemistry of the butane isomers in premixed low-pressure flames. Z. Phys. Chem. 225 (9-10) (2011) 1029-1054.

[53] N.M. Marinov; W.J. Pitz; C.K. Westbrook; A.M. Vincitore; M.J. Castaldi; S.M. Senkan; C.F. Melius, Aromatic and polycyclic aromatic hydrocarbon formation in a laminar premixed n-butane flame. Combust. Flame 114 (1-2) (1998) 192-213.

[54] A. Brockhinke; A. Bülter; J.C. Rolon; K. Kohse-Höinghaus, ps-LIF measurements of minor species concentration in a counterflow diffusion flame interacting with a vortex. Appl. Phys. B 72 (4) (2001) 491-496.

[55] H. Wang; X. You; A.V. Joshi; S.G. Davis; A. Laskin; F.N. Egolfopoulos; C.K. Law, USC Mech Version II. High-Temperature Combustion Reaction Model of $\mathrm{H}_{2} / \mathrm{CO} / \mathrm{C}_{1}-\mathrm{C}_{4}$ Compunds, http://ignis.usc.edu/USC_Mech_II.htm, May 2007.

[56] H.F. Jin; A. Cuoci; A. Frassoldati; T. Faravelli; Y.Z. Wang; Y.Y. Li; F. Qi, Experimental and kinetic modeling study of PAH formation in methane coflow diffusion flames doped with n-butanol. Combust. Flame 161 (3) (2014) 657-670.

[57] S.A. Skeen; B. Yang; H.A. Michelsen; J.A. Miller; A. Violi; N. Hansen, Studies of laminar opposed-flow diffusion flames of acetylene at low-pressures with photoionization mass spectrometry. Proc. Combust. Inst. 34 (2013) 1067-1075.

[58] F.N. Egolfopoulos; N. Hansen; Y. Ju; K. Kohse-Höinghaus; C.K. Law; F. Qi, Advances and challenges in laminar flame experiments and implications for combustion chemistry. Progr. Energy Combust. Sci. 43 (2014) 36-67.

[59] N. Hansen; T.A. Cool; P.R. Westmoreland; K. Kohse-Höinghaus, Recent contributions of flame-sampling molecular-beam mass spectrometry to a fundamental understanding of combustion chemistry. Prog. Energy Combust. Sci. 35 (2) (2009) 168-191.

[60] M.V. Heitor; A.L.N. Moreira, Thermocouples and sample probes for combustion studies. Prog. Energy Combust. Sci. 19 (3) (1993) 259-278.

[61] U. Struckmeier; P. Oßwald; T. Kasper; L. Böhling; M. Heusing; M. Köhler; A. Brockhinke; K. Kohse-Höinghaus, Sampling probe influences on temperature and species concentrations in molecular beam mass spectroscopic investigations of flat premixed low-pressure flames. Z. Phys. Chem. 223 (4-5) (2009) 503-537.

[62] L. Figura; F. Carbone; A. Gomez, Challenges and artifacts of probing high-pressure counterflow laminar diffusion flames. Proc. Combust. Inst. 35 (2015) 1871-1878.

[63] V. Gururajan; F.N. Egolfopoulos; K. Kohse-Höinghaus, Direct numerical simulations of probe effects in low-pressure flame sampling. Proc. Combust. Inst. 35 (2015) 821-829.

[64] F. Qi, Combustion chemistry probed by synchrotron VUV photoionization mass spectrometry. Proc. Combust. Inst. 34 (2013) 33-63.

[65] K. Moshammer; S. Vranckx; H.K. Chakravarty; P. Parab; R.X. Fernandes; K. KohseHöinghaus, An experimental and kinetic modeling study of 2-methyltetrahydrofuran flames. Combust. Flame 160 (12) (2013) 2729-2743. 
[66] N. Hansen; S.J. Klippenstein; P.R. Westmoreland; T. Kasper; K. Kohse-Höinghaus; J. Wang; T.A. Cool, A combined ab initio and photoionization mass spectrometric study of polyynes in fuel-rich flames. Phys. Chem. Chem. Phys. 10 (3) (2008) 366-374.

[67] K. Moshammer; A.W. Jasper; D.M. Popolan-Vaida; A. Lucassen; P. Dievart; H. Selim; A.J. Eskola; C.A. Taatjes; S.R. Leone; S.M. Sarathy; Y. Ju; P. Dagaut; K. KohseHöinghaus; N. Hansen, Detection and identification of the keto-hydroperoxide $\left(\mathrm{HOOCH} \mathrm{OCHO}_{2} \mathrm{O}\right.$ and other intermediates during low-temperature oxidation of dimethyl ether. J. Phys. Chem. A 119 (28) (2015) 7361-7374.

[68] K. Schofield, Large scale chemical kinetic models of fossil fuel combustion: Adequate as engineering models-no more, no less. Energy Fuels 26 (9) (2012) 5468-5480.

[69] S.E. Stein; A. Fahr, High-temperature stabilities of hydrocarbons. J. Phys. Chem. 89 (17) (1985) 3714-3725.

[70] C. Wentrup; H.W. Winter; D. Kvaskoff, $C_{9} H_{8}$ pyrolysis. o-Tolylacetylene, indene, 1 indenyl, and biindenyls and the mechanism of indene pyrolysis. J. Phys. Chem. A 119 (24) (2015) 6370-6376.

[71] F.T. Zhang; R.I. Kaiser; V.V. Kislov; A.M. Mebel; A. Golan; M. Ahmed, A VUV photoionization study of the formation of the indene molecule and its isomers. J. Phys. Chem. Lett. 2 (14) (2011) 1731-1735.

[72] J.D. Bittner; J.B. Howard, Composition profiles and reaction mechanism in a nearsooting premixed benzene/oxygen/argon flame. Proc. Combust. Inst. 18 (1) (1981) 11051116.

[73] F. Dubnikova; A. Lifshitz, Ring expansion and isomerization in methyl indene and methylene indene radicals. Quantum chemical and transition-state theory calculations. Isr. J. Chem. 43 (3-4) (2003) 325-338.

[74] A. Lifshitz; C. Tamburu; A. Suslensky; F. Dubnikova, Decomposition, isomerization, and ring expansion in 2-methylindene: Single-pulse shock tube and modeling study. J. Phys. Chem. A 108 (16) (2004) 3430-3438.

[75] A.W. Jasper; N. Hansen, Hydrogen-assisted isomerizations of fulvene to benzene and of larger cyclic aromatic hydrocarbons. Proc. Combust. Inst. 34 (2013) 279-287.

[76] B. Shukla; M. Koshi, Importance of fundamental sp, sp(2), and $s p(3)$ hydrocarbon radicals in the growth of polycyclic aromatic hydrocarbons. Anal. Chem. 84 (11) (2012) 5007-5016.

[77] K.H. Homann, Fullerenes and soot formation - New pathways to large particles in flames. Angew. Chem. Int. Ed. 37 (18) (1998) 2435-2451.

[78] M. Frenklach; H. Wang, Detailed modeling of soot particle nucleation and growth. Proc. Combust. Inst. 23 (1) (1991) 1559-1566.

[79] R.K. Sreeruttun; P. Ramasami; C.S. Wannere; A.C. Simmonett; H.F. Schaefer, pi and alpha-phenylethynyl radicals and their isomers $o-, m$-, and p-ethynylphenyl: Structures, energetics, and electron affinities. J. Phys. Chem. A 112 (13) (2008) 2838-2845.

[80] X. Gu; Y. Guo; F. Zhang; A.M. Mebel; R.I. Kaiser, A crossed molecular beams study of the reaction of dicarbon molecules with benzene. Chem. Phys. Lett. 436 (1-3) (2007) 714.

[81] D.S.N. Parker; R.I. Kaiser; T.P. Troy; M. Ahmed, Hydrogen abstraction/acetylene addition revealed. Angew. Chem. Int. Ed. 53 (30) (2014) 7740-7744. 
[82] H. Sabbah; L. Biennier; S.J. Klippenstein; I.R. Sims; B.R. Rowe, Exploring the role of PAHs in the formation of soot: Pyrene dimerization. J. Phys. Chem. Lett. 1 (19) (2010) 2962-2967.

[83] C.A. Schuetz; M. Frenklach, Nucleation of soot: Molecular dynamics simulations of pyrene dimerization. Proc. Combust. Inst. 29 (2002) 2307-2314.

[84] T.S. Totton; A.J. Misquitta; M. Kraft, A quantitative study of the clustering of polycyclic aromatic hydrocarbons at high temperatures. Phys. Chem. Chem. Phys. 14 (12) (2012) 4081-4094.

[85] J.H. Miller, Aromatic excimers: evidence for polynuclear aromatic hydrocarbon condensation in flames. Proc. Combust. Inst. 30 (2005) 1381-1388.

[86] C. Cavallotti; S. Mancarella; R. Rota; S. Carra, Conversion of $C_{5}$ into $C_{6}$ cyclic species through the formation of $C_{7}$ intermediates. J. Phys. Chem. A 111 (19) (2007) 3959-3969.

[87] S. Fascella; C. Cavallotti; R. Rota; S. Carra, Quantum chemistry investigation of key reactions involved in the formation of naphthalene and indene. J. Phys. Chem. A 108 (17) (2004) 3829-3843.

[88] A. Giordana; A. Maranzana; G. Tonachini, Carbonaceous nanoparticle molecular inception from radical addition and van der Waals coagulation of polycyclic aromatic hydrocarbon-based systems. A theoretical study. J. Phys. Chem. C 115 (35) (2011) 17237-17251.

[89] S.A. Skeen; B. Yang; A.W. Jasper; W.J. Pitz; N. Hansen, Chemical Structures of LowPressure Premixed Methylcyclohexane Flames as Benchmarks for the Development of a Predictive Combustion Chemistry Model. Energy Fuels 25 (12) (2011) 5611-5625. 